\title{
DWPF GC FILTER ASSEMBLY SAMPLING AND ANALYSIS
}

C. J. Bannochie

K. J. Imrich

November 2009

Savannah River National Laboratory

Savannah River Nuclear Solutions

Aiken, SC 29808

Prepared for the U.S. Department of Energy Under

Contract Number DE-AC09-08SR22470

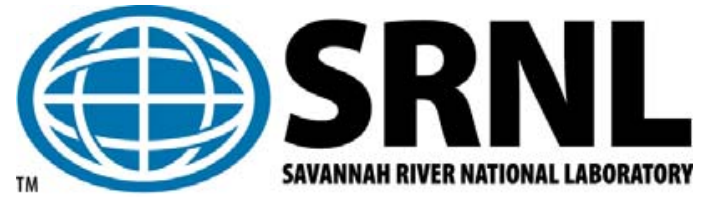




\section{DISCLAIMER}

This work was prepared under an agreement with and funded by the U.S. Government. Neither the U. S. Government or its employees, nor any of its contractors, subcontractors or their employees, makes any express or implied:

1. warranty or assumes any legal liability for the accuracy, completeness, or for the use or results of such use of any information, product, or process disclosed; or

2. representation that such use or results of such use would not infringe privately owned rights; or

3. endorsement or recommendation of any specifically identified commercial product, process, or service.

Any views and opinions of authors expressed in this work do not necessarily state or reflect those of the United States Government, or its contractors, or subcontractors.

Printed in the United States of America

Prepared For

U.S. Department of Energy 
Key Words: $D W P F, S B 4, G C$ Line Filter, HEPA, HEME

Retention: PERMANENT

\section{DWPF GC FILTER ASSEMBLY SAMPLING AND ANALYSIS}

C. J. Bannochie

K. J. Imrich

November 2009

Savannah River National Laboratory Savannah River Nuclear Solutions Aiken, SC 29808

Prepared for the U.S. Department of Energy Under Contract Number DE-AC09-08SR22470

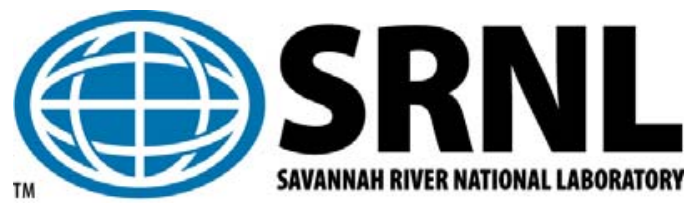




\section{REVIEWS AND APPROVALS}

\section{AUTHOR(S):}

C. J. Bannochie, Process Technology Programs

Date

K. J. Imrich, Materials Composition \& Welding Technology

Date

TECHNICAL REVIEWERS:

N. E. Bibler, Process Technology Programs

Date

\section{APPROVERS}

C. C. Herman, Manager, Process Technology Programs

Date

S. L. Marra, Manager, Research Programs, E\&CPT

Date

J. E. Occhipinti, SRR Engineering

Date 


\section{EXECUTIVE SUMMARY}

On March 18, 2009 a Defense Waste Processing Facility (DWPF) GC Line Filter Assembly was received at the Savannah River National Laboratory (SRNL). This filter assembly was removed from operation following the completion of Sludge Batch 4 processing in the DWPF. Work on this sample was requested in a Technical Assistance Request. ${ }^{1}$ This document reports the pictures, observations, samples collected, and analytical results for the assembly. The assembly arrived at SRNL separated into its three component filters: high efficiency particulate air (HEPA)-1, HEPA-2, and a high efficiency mist evaporator (HEME).

Each stage of the assembly's media was sampled and examined visually and by scanning electron microscopy (SEM). Solids built up in the filter housing following the first stage HEME, were dissolved in dilute nitric acid and analyzed by ICP-AES and the undissolved white solids were analyzed by x-ray diffraction (XRD).

The vast majority of the material in each of the three stages of the DWPF GC Line Filter Assembly appears to be contaminated with a $\mathrm{Hg}$ compound that is $\sim 59 \mathrm{wt} \% \mathrm{Hg}$ on a total solids basis. The $\mathrm{Hg}$ species was identified by XRD analysis to contain a mixture of $\mathrm{Hg}_{4}(\mathrm{OH})\left(\mathrm{NO}_{3}\right)_{3}$ and $\mathrm{Hg}_{10}(\mathrm{OH})_{4}\left(\mathrm{NO}_{3}\right)_{6}$. Only in the core sample of the second stage HEPA, did this material appear to be completely covering portions of the filter media, possibly explaining the pressure drops observed by DWPF. The fact that the material migrates through the HEME filter and both HEPA filters, and that it was seen collecting on the outlet side of the HEME filter, would seem to indicate that these filters are not efficient at removing this material.

Further SRAT off-gas system modeling should help determine the extent of Hg breakthrough past the Mercury Water Wash Tank (MWWT). The SRAT off-gas system has not been modeled since startup of the facility. Improvements to the efficiency of Hg stripping prior to the ammonia scrubber would seem to be the only way to prevent/mitigate the formation of the compounds found in the GC Line Filter Assembly filters and therefore prevent pluggage of this filter assembly.

\footnotetext{
${ }^{1}$ Wingard, B. R., GC Filter Assembly Sample and Analysis: Technical Assistance Request, HLE-DWPF-TAR-2009-
} 002, Savannah River Site, Aiken, SC 29808 (2009). 
TABLE OF CONTENTS

EXECUTIVE SUMMARY vi

LIST OF FIGURES viii

LIST OF TABLES $\mathrm{x}$

LIST OF ACRONYMS/ABBREVIATIONS xi

1.0 INTRODUCTION AND BACKGROUND 1

2.0 APPROACH AND RESULTS 3

2.1 Filter Assembly Schematic 3

2.2 Filter Component Sampling 3

2.2.1 HEME Sample Characterization $\quad 8$

$\begin{array}{lr}\text { 2.2.2 HEPA-1 Sample Characterization } & 13\end{array}$

2.2.3 HEPA-2 Sample Characterization $\quad 18$

2.3 Analytical Results 27

3.0 DISCUSSION 29

3.1 Filter Deposits $\quad 29$

3.2 Historical Hg Compounds in Offgas Lines $\quad 29$

3.3 Evaluation of Total Hg Present 30

$\begin{array}{ll}\text { 4.0 CONCLUSIONS } & 31\end{array}$

5.0 REFERENCES 33

6.0 ACKNOWLEDGEMENTS 35 


\section{LIST OF FIGURES}

Figure 1. DWPF GC Line Filter Assembly 3

Figure 2. Core sampling tool developed for the DWPF GC Line Filter Assembly..................... 4

Figure 3. Core sampling tool close-up showing relative size and containing a sample of filter media.

Figure 4. DWPF GC Line Filter Assembly HEME. Orientation has the inlet at the top, so the flow would be from the top down in this image.

Figure 5. DWPF GC Line Filter Assembly HEME, Outlet Side. White solid deposits can be seen on the screen below and on the inside walls of the housing.

Figure 6. DWPF GC Line Filter Assembly HEME, Outlet Side after partial removal of retaining rods and mesh screen ....

Figure 7. DWPF GC Line Filter Assembly HEME filter media removed with coring tool.......... 6

Figure 8. DWPF GC Line Filter Assembly HEME, Inlet Side............................................. 6

Figure 9. DWPF GC Line Filter Assembly HEME filter media removed from the outlet side. ... 6

Figure 10. DWPF GC Line Filter Assembly HEPA-1, Inlet Side ......................................... 7

Figure 11. DWPF GC Line Filter Assembly HEPA-1, Outlet Side showing sampling hole in

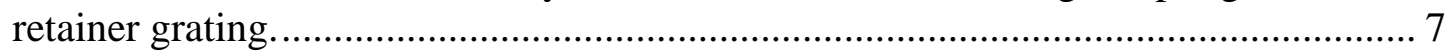

Figure 12. DWPF GC Line Filter Assembly HEPA-1, Outlet Side......................................... 7

Figure 13. DWPF GC Line Filter Assembly HEPA-1 filter media sample, showing inlet side on the left.

Figure 14. DWPF GC Line Filter Assembly HEPA-2, Inlet Side .............................................. 8

Figure 15. DWPF GC Line Filter Assembly HEPA-2, Outlet Side.......................................... 8

Figure 16. DWPF GC Line Filter Assembly HEPA-2, Outlet Side showing sampling hole in retainer grating

Figure 17. DWPF GC Line Filter Assembly HEPA-2 filter media sample, showing inlet side on the left.

Figure 18. Raster Scan Area of DWPF GC Line Filter Assembly HEME, Inlet Side, Filter Media

Figure 19. SEM EDX raster scan spectrum of the elements found in the HEME area outlined in

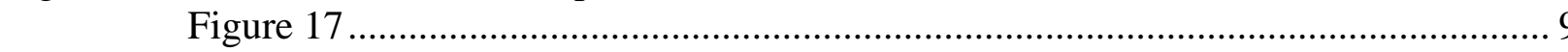

Figure 20. SEM image of DWPF GC Line Filter Assembly HEME, Inlet side, filter media ..... 10

Figure 21. SEM EDX spectrum of the HEME, Spot 1 in Figure 19...................................... 10

Figure 22. SEM EDX spectrum of the HEME Fiber Matrix in Figure 17............................... 11

Figure 23. SEM image of DWPF GC Line Filter Assembly HEME, Outlet side, filter media... 11

Figure 24. DWPF GC Line Filter Assembly Post-HEME Solids ........................................... 12

Figure 25. SEM EDX spectrum of the post-HEME solids in Figure 23................................... 12

Figure 26. Raster Scan Area of DWPF GC Line Filter Assembly HEPA-1, Inlet Side, Filter

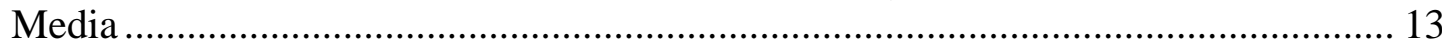

Figure 27. SEM EDX raster scan spectrum of the elements found in the area outlined in Figure

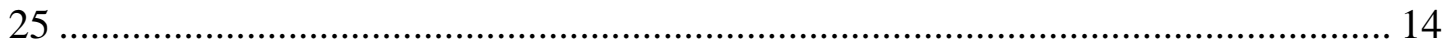

Figure 28. SEM EDX spectrum of the least contaminated area of the filter fiber matrix.......... 14

Figure 29. SEM image of DWPF GC Line Filter Assembly HEPA-1, Inlet side, filter media... 15

Figure 30. SEM EDX spectrum of HEPA-1, Spot 1 in Figure 28....................................... 15

Figure 31. SEM EDX spectrum of HEPA-1, Spot 2 in Figure 28 ........................................ 16 
Figure 32. Raster Scan of DWPF GC Line Filter Assembly HEPA-1, Outlet Side, Filter Media 16

Figure 33. SEM image of DWPF GC Line Filter Assembly HEPA-1, outlet side, filter media . 17

Figure 34. SEM EDX spectrum of HEPA-1, Spot 1 in Figure 32. 17

Figure 35. Raster Scan Area of DWPF GC Line Filter Assembly HEPA-2, Inlet Side, Filter Media.....

Figure 36. SEM EDX raster scan spectrum of the elements found in the HEPA-2 area outlined in Figure 34

Figure 37. SEM image of DWPF GC Line Filter Assembly HEPA-2, Inlet side, filter media ... 20

Figure 38. SEM EDX spectrum of HEPA-2, Spot 1 in Figure 36 ............................................ 20

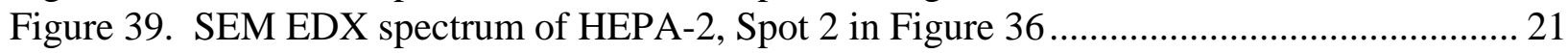

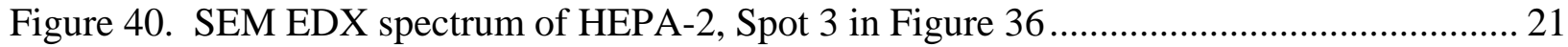

Figure 41. SEM image of DWPF GC Line Filter Assembly HEPA-2, Inlet side, filter media... 22

Figure 42. SEM EDX spectrum of HEPA-2, Spot 4 in Figure 40 ........................................... 22

Figure 43. SEM image of DWPF GC Line Filter Assembly HEPA-2, Inlet side, filter media... 23

Figure 44. SEM EDX spectrum of HEPA-2, Spot 5 in Figure 42 ......................................... 23

Figure 45. SEM EDX spectrum of HEPA-2, Spot 6 in Figure 42 .......................................... 24

Figure 46. Raster Scan Area of DWPF GC Line Filter Assembly HEPA-2, Outlet Side, Filter

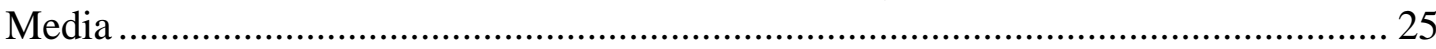

Figure 47. SEM EDX raster scan spectrum of the elements found in the HEPA-2 area outlined in Figure 45 25

Figure 48. SEM image of DWPF GC Line Filter Assembly HEPA-2, Outlet side, filter media 26

Figure 49. SEM EDX spectrum of HEPA-2, Spot 1 in Figure 47 .......................................... 26

Figure 50. X-ray diffraction spectrum from white solids collected from the HEME outlet of the DWPF GC Line Filter Assembly 


\section{LIST OF TABLES}

Table 1. DWPF GC Line Filter Assembly Dose Rates (mrem).............................................. 1

Table 2. Elemental composition of the white solids obtained from the DWPF GC Line Filter

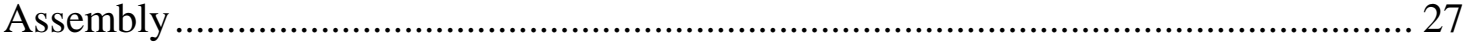




\section{LIST OF ACRONYMS/ABBREVIATIONS}

$\begin{array}{ll}\text { AD } & \text { Analytical Development } \\ \text { CV-AA } & \text { Cold Vapor - Atomic Absorption Spectroscopy } \\ \text { DI } & \text { Deionized } \\ \text { DWPF } & \text { Defense Waste Processing Facility } \\ \text { EDX } & \text { Energy Dispersive X-Ray } \\ \text { FAVC } & \text { Formic Acid Vent Condenser } \\ \text { IC } & \text { Ion Chromatography } \\ \text { ICP-AES } & \text { Inductively Coupled Plasma - Atomic Emission Spectroscopy } \\ \text { HEME } & \text { High Efficiency Mist Evaporator } \\ \text { HEPA } & \text { High Efficiency Particulate Air } \\ \text { M } & \text { Molar } \\ \text { mL } & \text { Milliliter } \\ \text { MWWT } & \text { Mercury Water Wash Tank } \\ \text { N/A } & \text { Not Available } \\ \text { N/D } & \text { Not Detected } \\ \text { N/M } & \text { Not Measured } \\ \text { PVV } & \text { Process Vessel Vent } \\ \text { RSD } & \text { Relative Standard Deviation } \\ \text { SB4 } & \text { Sludge Batch 4 } \\ \text { SEM } & \text { Scanning Electron Microscopy } \\ \text { SMECT } & \text { Slurry Mix Evaporator Condensate Tank } \\ \text { SRAT } & \text { Slurry Receipt Adjustment Tank } \\ \text { SRNL } & \text { Savannah River National Laboratory } \\ \text { SRR } & \text { Savannah River Remediation } \\ \text { SRS } & \text { Savannah River Site } \\ \text { Std. Dev. } & \text { Standard Deviation } \\ \text { TAR } & \text { Technical Assistance Request } \\ \text { TS } & \text { Total Solids } \\ \text { Wt \% } & \text { Weight Percent } \\ \text { XRD } & \text { X-Ray Diffraction } \\ & \end{array}$




\subsection{INTRODUCTION AND BACKGROUND}

On March 18, 2009 a Defense Waste Processing Facility (DWPF) GC Line Filter Assembly was received at the Savannah River National Laboratory (SRNL). This filter assembly was removed from operation following the completion of Sludge Batch 4 processing in the DWPF. Work on this sample was requested in a Technical Assistance Request. ${ }^{1}$ This document reports the pictures, observations, samples collected, and analytical results for the assembly. The assembly arrived at SRNL separated into its three component filters: high efficiency particulate air (HEPA)-1, HEPA-2, and a high efficiency mist evaporator (HEME). The initial intent was to conduct a gamma survey of the assembly to determine if any blockage point could be identified along its length. When the assembly components arrived in SRNL individually bagged, the need for this survey became less clear. Table 1 presents the dose rates reported for the assembly by both DWPF and SRNL.

Table 1. DWPF GC Line Filter Assembly Dose Rates (mrem)

\begin{tabular}{lcc}
\hline Component & DWPF & SRNL \\
& & \\
\hline HEME & 1 & N/D \\
whole body & 240 & N/M \\
skin & 3200 & 1000 \\
extremity & & \\
HEPA-1 & 1 & N/D \\
whole body & 75 & N/M \\
skin & 200 & 200 \\
extremity & & \\
HEPA-2 & 0.5 & N/D \\
whole body & 30 & N/M \\
skin & 48 & 12 \\
extremity &
\end{tabular}


SRNL-STI-2009-00602

Revision 0

This page intentionally left blank. 


\subsection{APPROACH AND RESULTS}

\subsection{Filter Assembly Schematic}

The DWPF GC Line Filter Assembly is comprised of three component filters: HEME, HEPA-1, and HEPA-2. Shown in Figure 1 is a schematic of the assembly. Note in this diagram, the final HEPA stage is shown at a $90^{\circ}$ angle to the first HEPA stage. The current assembly design has all three filters in a linear arrangement.

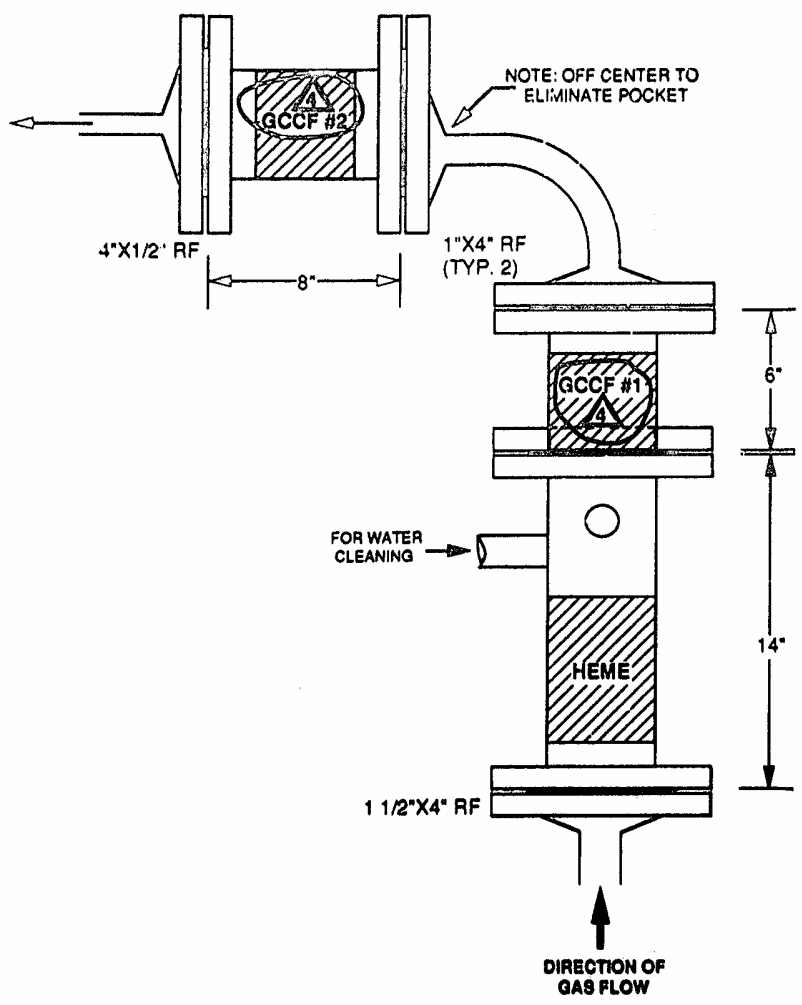

Figure 1. DWPF GC Line Filter Assembly

\subsection{Filter Component Sampling}

Figure 2 captures the sampling tool developed in SRNL for taking core samples of the filters from the DWPF GC Line Filter Assembly (shown in Figure 1). The tool has a sharp leading edge that cuts the filter media and a hollow core which collects the sample (Figure 3) as the sampler passes through the filter media. The core sample is then removed from the sampler using the polymer rod shown at the bottom of Figure 2. Sampling was done from the outlet side so that the coring tool would move through 
the filter media from, what was believed would be, the less contaminated to the more contaminated end of the media.

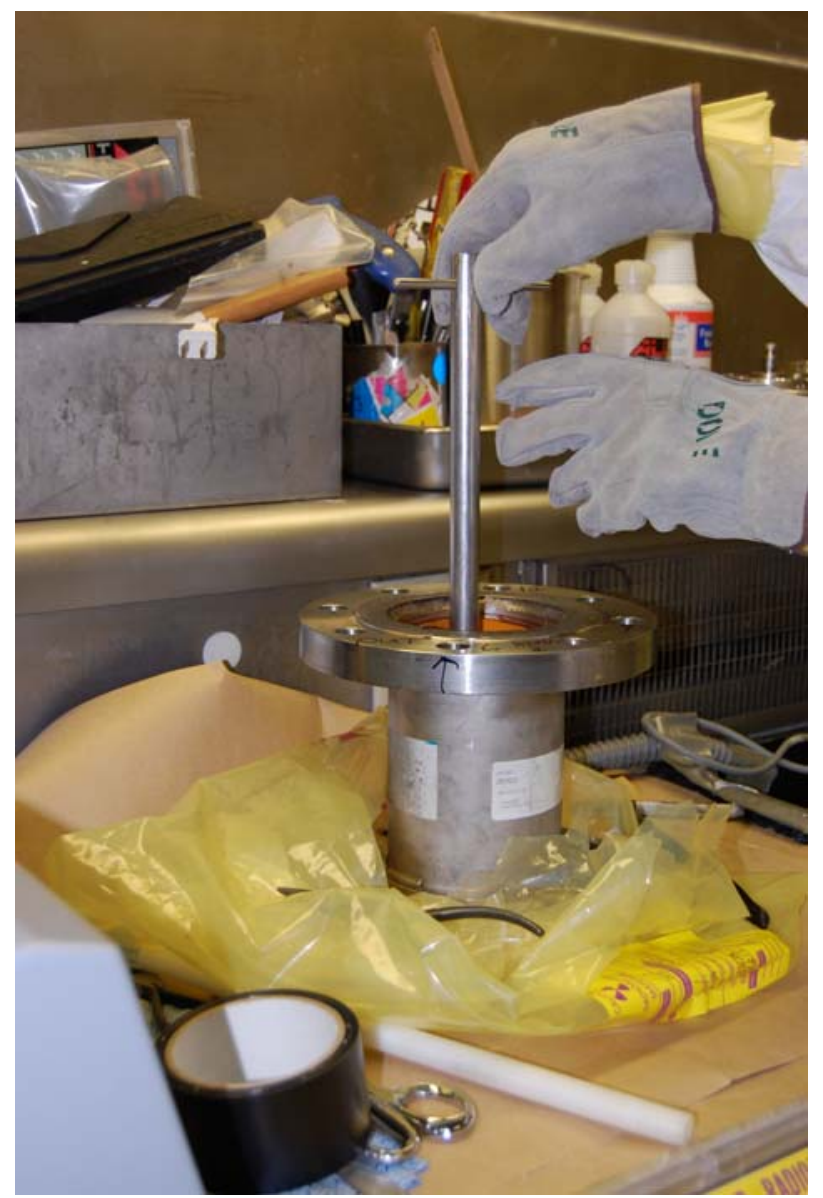

Figure 2. Core sampling tool developed for the DWPF GC Line Filter Assembly.

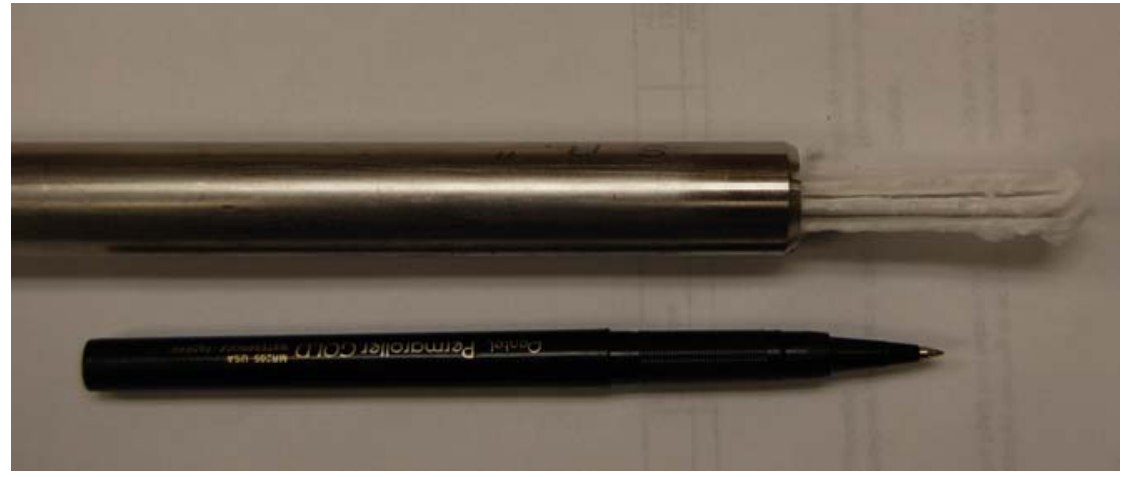

Figure 3. Core sampling tool close-up showing relative size and containing a sample of filter media

Figure 4 and Figure 5 show the DWPF GC Line Filter Assembly Stage 1 HEME housing and the outlet side looking into the filter, respectively. White deposits are clearly visible on the inside, outlet end of this filter. 


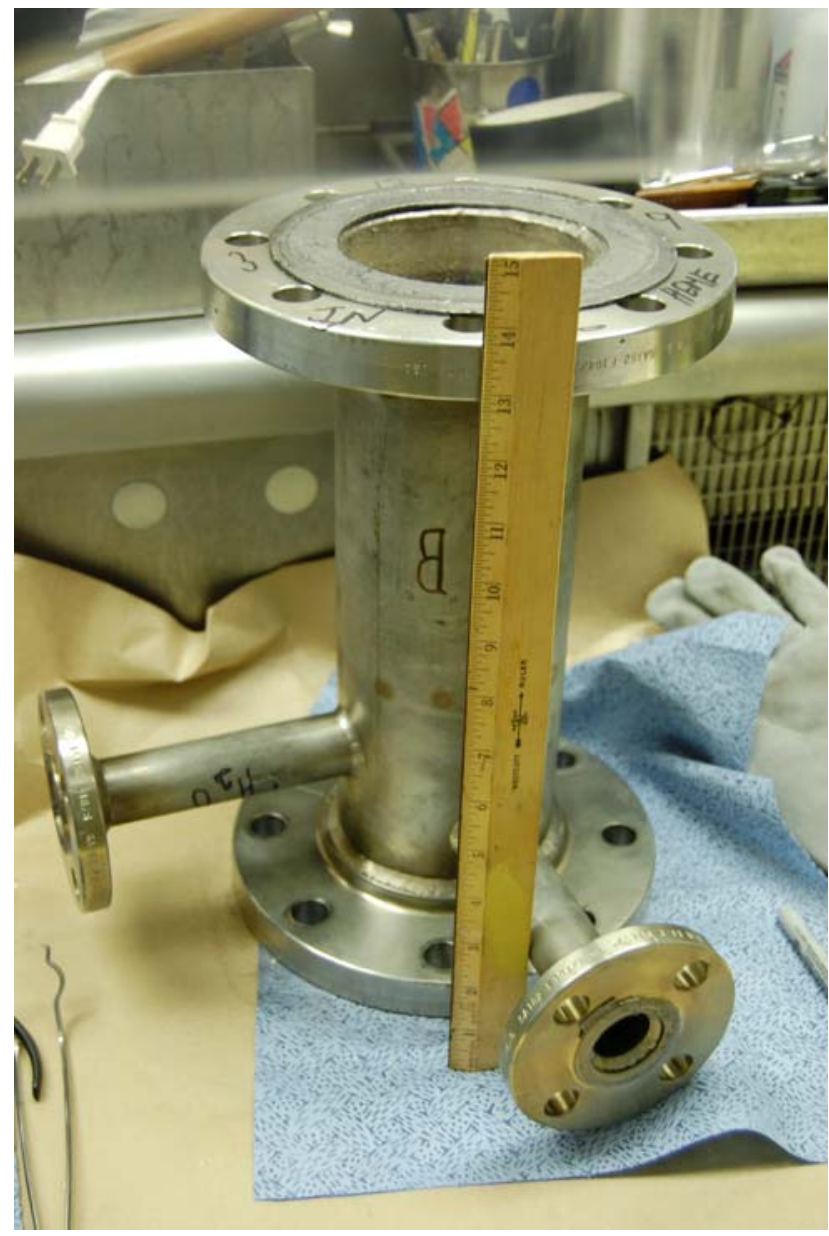

Figure 4. DWPF GC Line Filter Assembly HEME. Orientation has the inlet at the top, so the flow would be from the top down in this image.

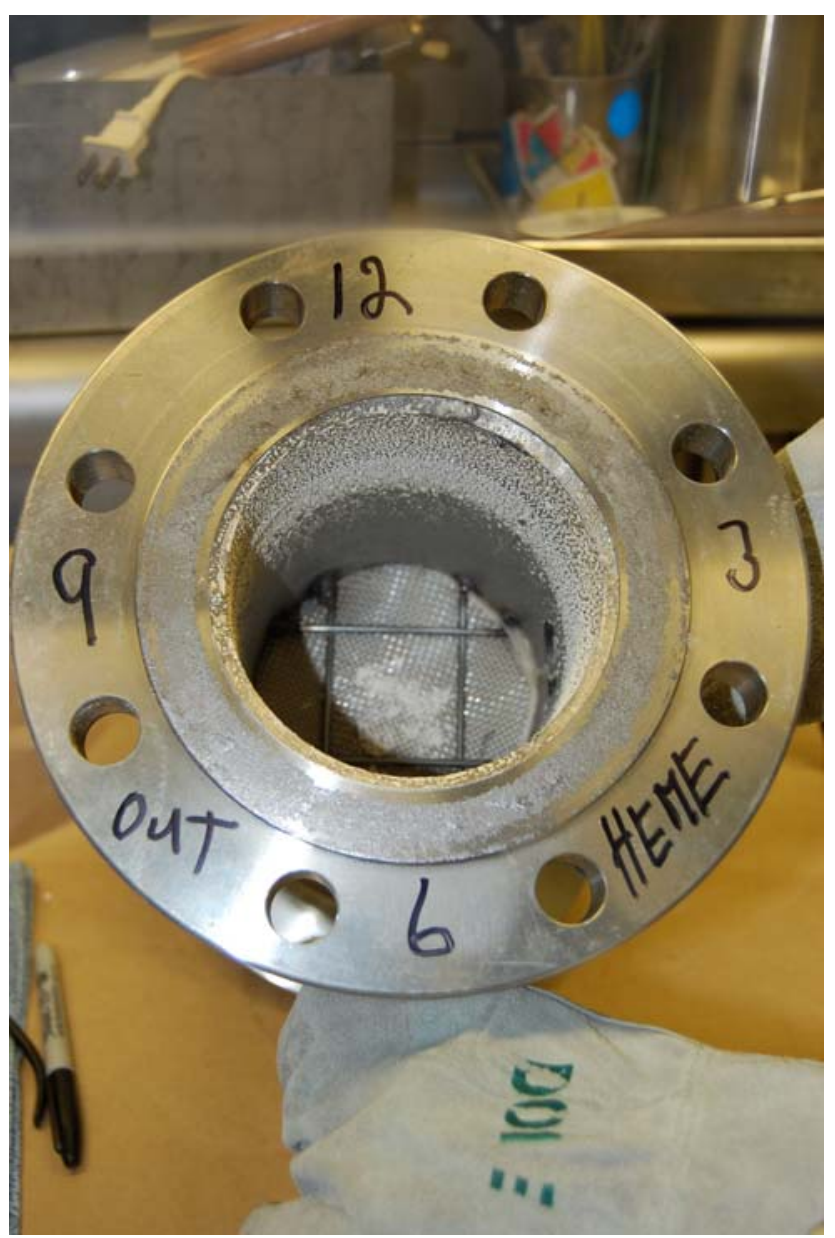

Figure 5. DWPF GC Line Filter Assembly HEME, Outlet Side. White solid deposits can be seen on the screen below and on the inside walls of the housing.

The HEME white solids deposits were collected before attempting sampling with the coring tool. It was difficult to cut the media retaining screen on the HEME due to the large rods that protect it. These rods were cut off and removed as shown in Figure 6. The two rods that were elevated above the screen could be cut relatively easily, but two of the rods were flush against the screen and therefore, difficult to grasp in the cutters. This screen may have been welded to the rods in several locations and hence could not be removed completely. The underlying HEME media is packed into the housing like cotton candy. The coring tool was ineffective at cutting through the fiberglass media and tended to rip and/or compact it during sampling (Figure 7). It should be noted that no solids were observed on the HEME's inlet side, neither on the media retaining screen nor on the surrounding housing walls (Figure 8). To get a sufficient sample of the HEME media, it was necessary to pull the media out of the compact bundle. The final sample of HEME media collected is shown in Figure 9. 


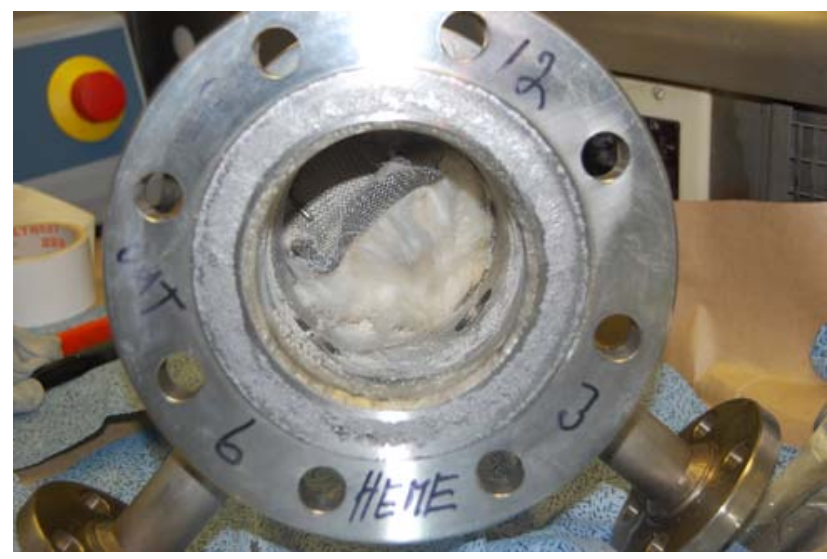

Figure 6. DWPF GC Line Filter Assembly HEME, Outlet Side after partial removal of retaining rods and mesh screen

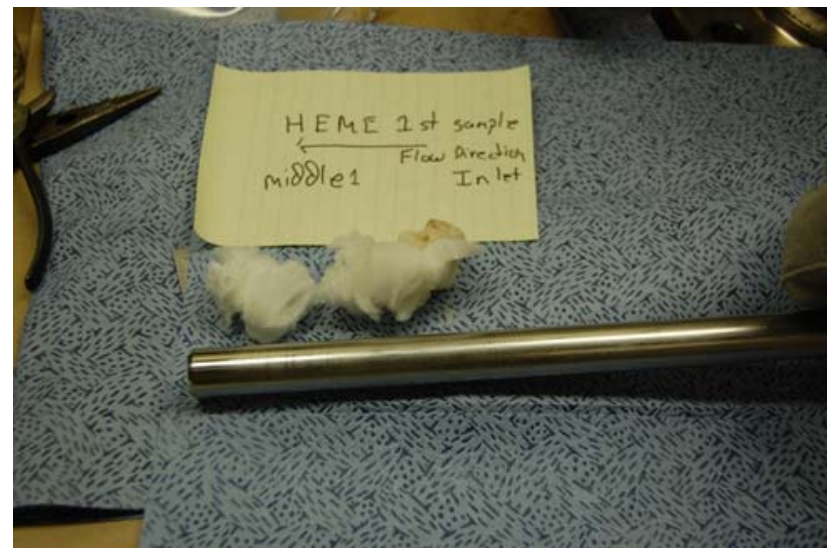

Figure 7. DWPF GC Line Filter Assembly HEME filter media removed with coring tool.

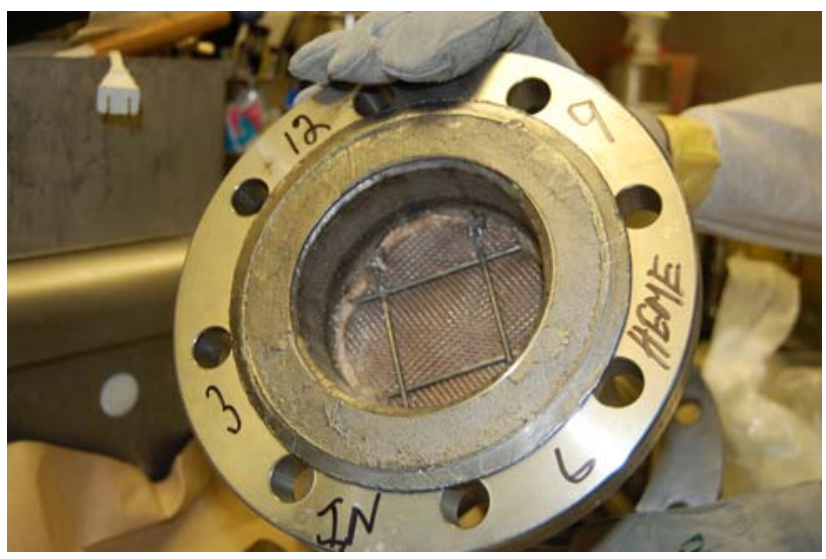

Figure 8. DWPF GC Line Filter Assembly HEME, Inlet Side

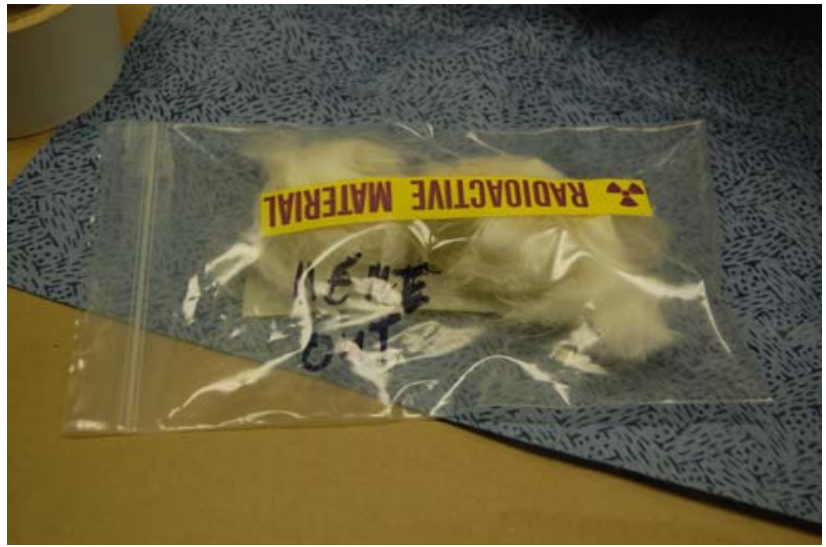

Figure 9. DWPF GC Line Filter Assembly HEME filter media removed from the outlet side.

Figure 10 through Figure 13 show the GC Line Filter Assembly's Stage 2 HEPA-1. Figure 10 and 12 show the inlet and outlet ends of the first HEPA filter. No visible deposits could be seen on the filter housing, screen, or surface of the filter media. A small amount of discoloration (light brown) can be seen at the tip of the core sample (Figure 13), but no loose solids fell from the removed filter media sample. If there had been a large buildup of solids on the media this would have resulted in visible solid residue on the colored towel, but no such solids were observed, hence there was no buildup of solids on the media. 
SRNL-STI-2009-00602

Revision 0

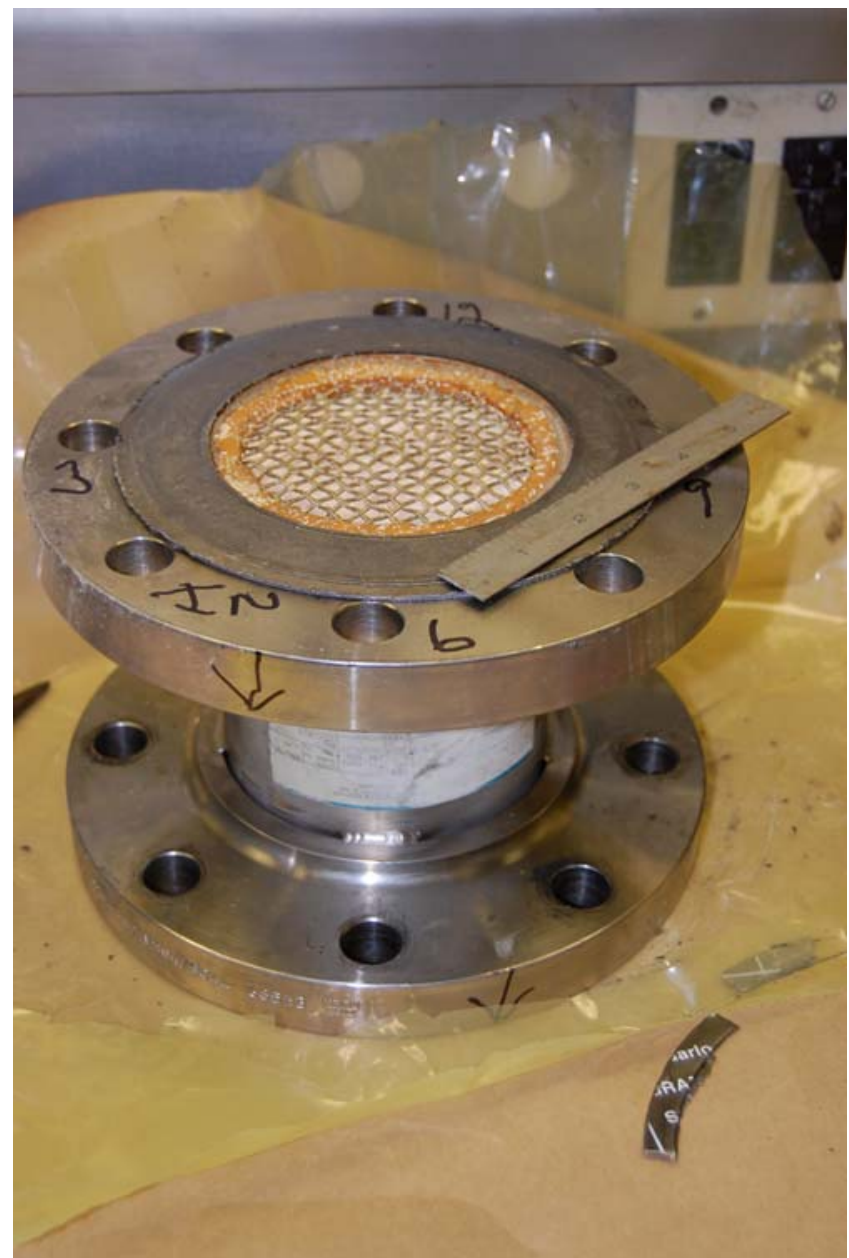

Figure 10. DWPF GC Line Filter Assembly HEPA-1, Inlet Side

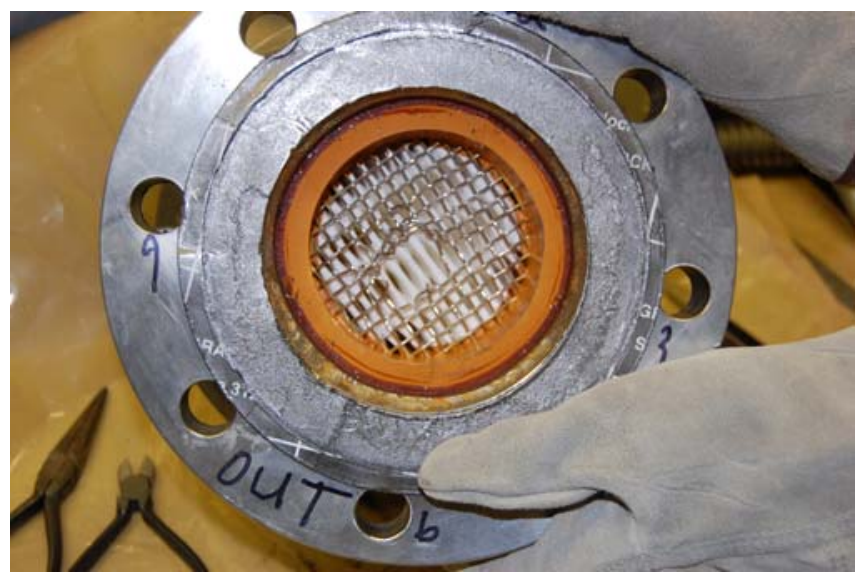

Figure 11. DWPF GC Line Filter Assembly HEPA-1, Outlet Side showing sampling hole in retainer grating.

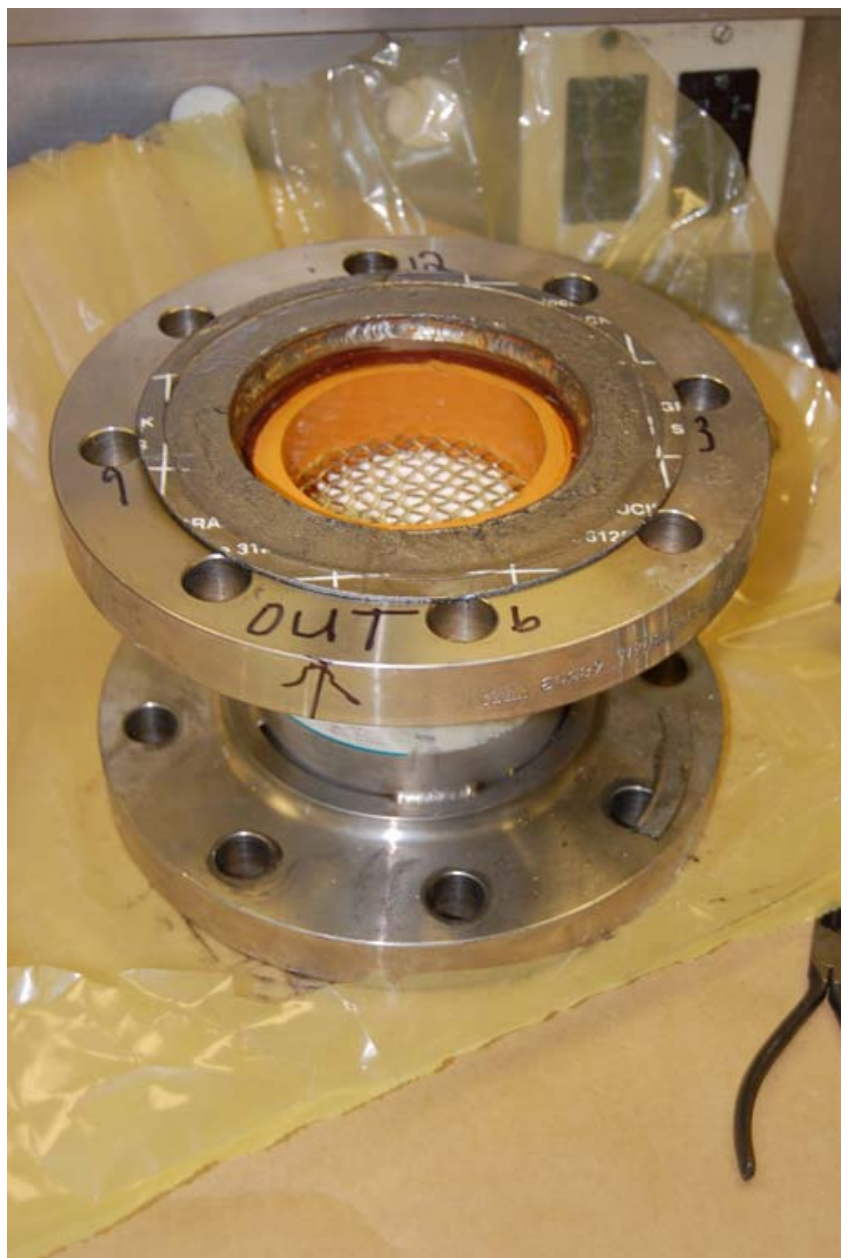

Figure 12. DWPF GC Line Filter Assembly HEPA-1, Outlet Side

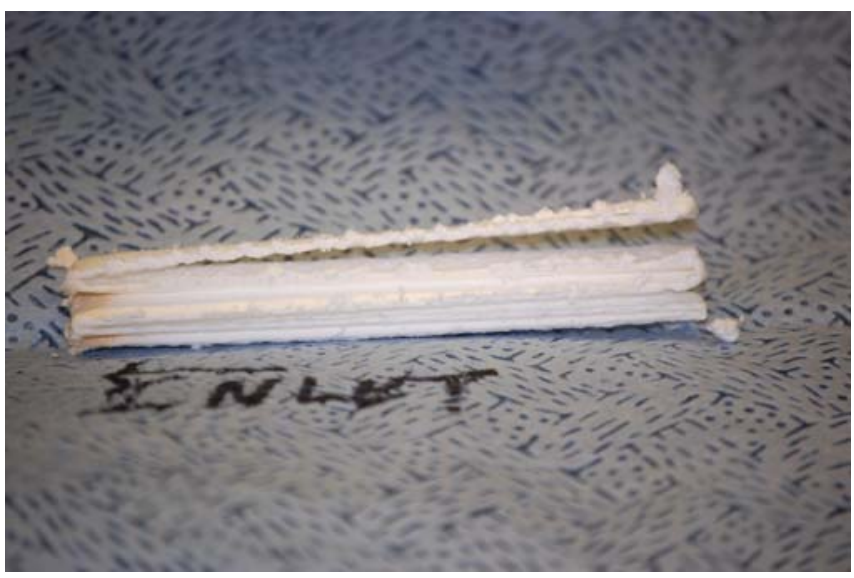

Figure 13. DWPF GC Line Filter Assembly HEPA-1 filter media sample, showing inlet side on the left. 
Figure 14 through Figure 16 show the GC Line Filter Assembly's Stage 3 HEPA-2. Figure 14 and Figure 15 show the inlet and outlet sides of HEPA-2, respectively.

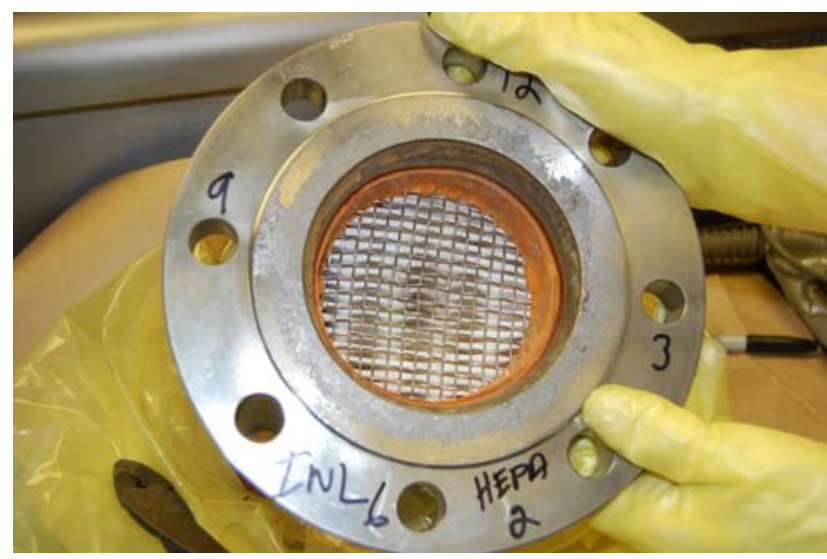

Figure 14. DWPF GC Line Filter Assembly HEPA-2, Inlet Side

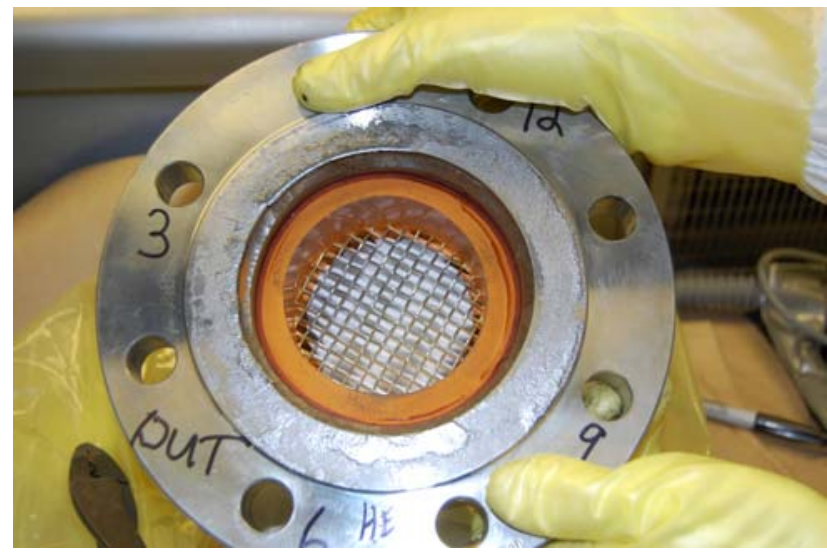

Figure 15. DWPF GC Line Filter Assembly HEPA-2, Outlet Side

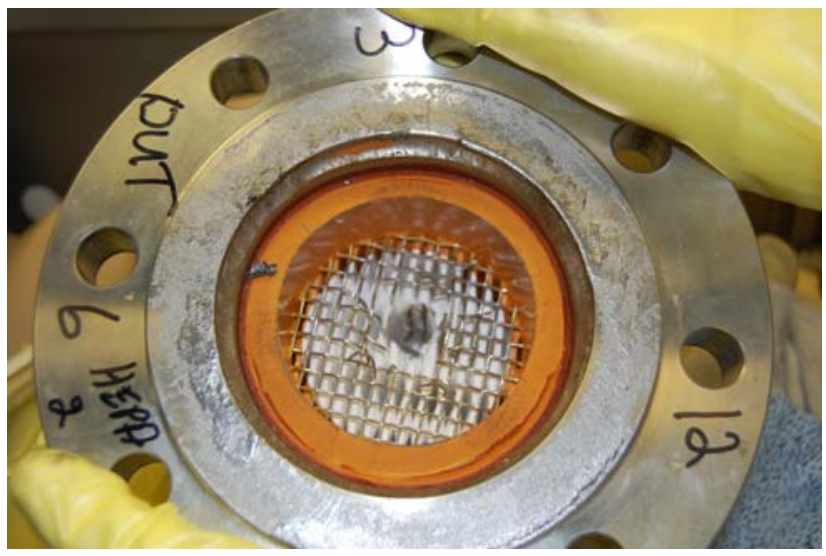

Figure 16. DWPF GC Line Filter Assembly HEPA-2, Outlet Side showing sampling hole in retainer grating

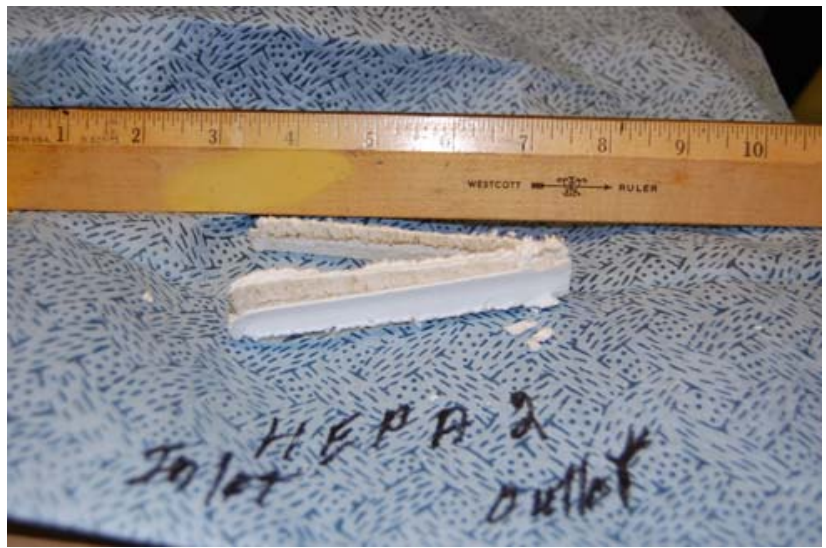

Figure 17. DWPF GC Line Filter Assembly HEPA-2 filter media sample, showing inlet side on the left.

The core sample from HEPA-2, shown in Figure 17, has a visible coating of white solids as can be observed by the smooth surface texture of the filter media. Compare this appearance to the rough texture of the media in Figure 13.

\subsubsection{HEME Sample Characterization}

A scanning electron microscopy (SEM) raster scans with energy dispersive x-ray (EDX) analysis were requested to get an overall impression of the elemental composition on the filter media. The fibrous nature of the HEME filter media is quite evident in Figure 18. Subtracting out the fiber matrix elemental 
composition shown in Figure 22 from that found in Figure 21, indicates the primary and almost exclusive, remaining component is a $\mathrm{Hg}$ containing material.

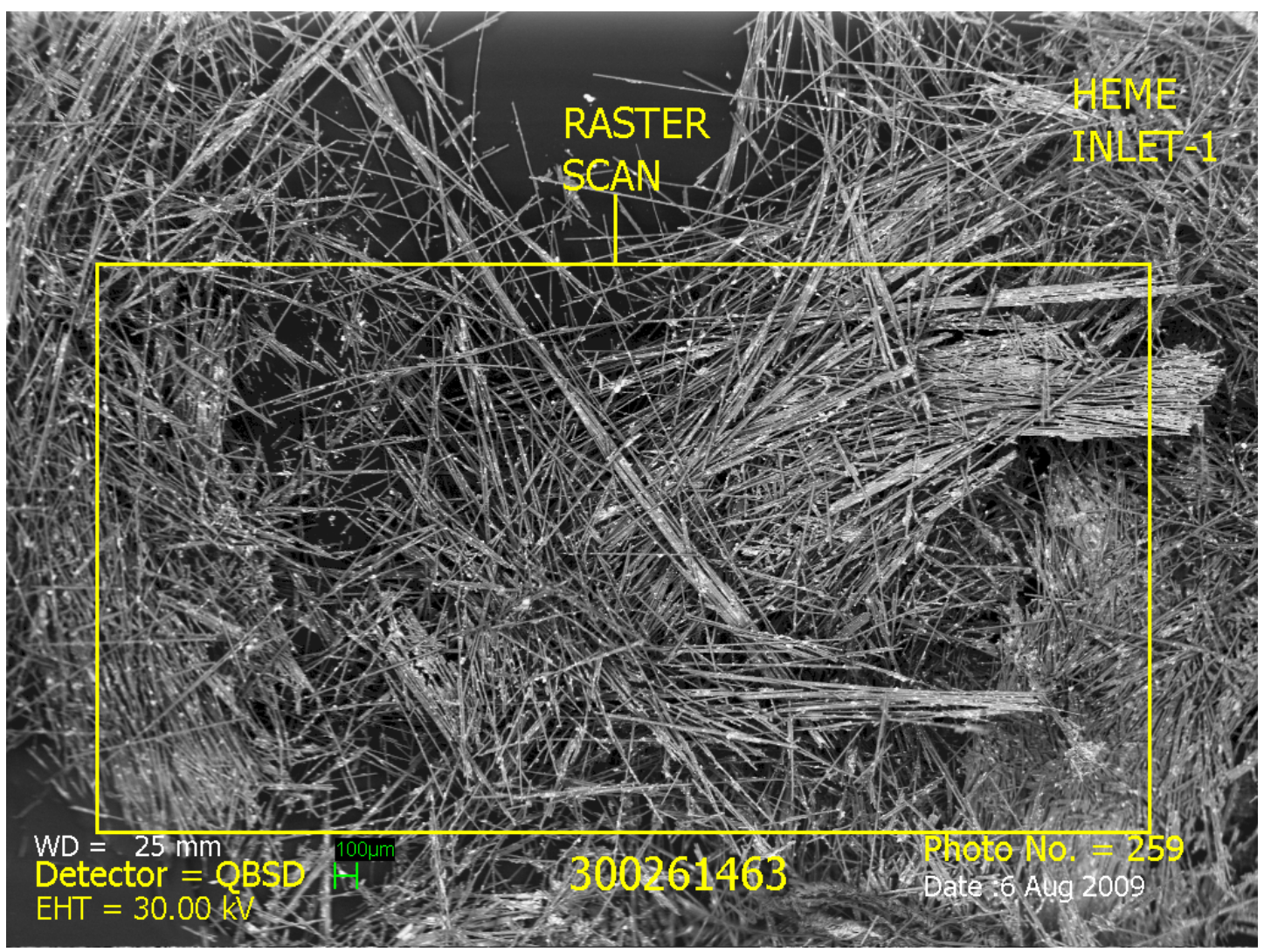

Figure 18. Raster Scan Area of DWPF GC Line Filter Assembly HEME, Inlet Side, Filter Media

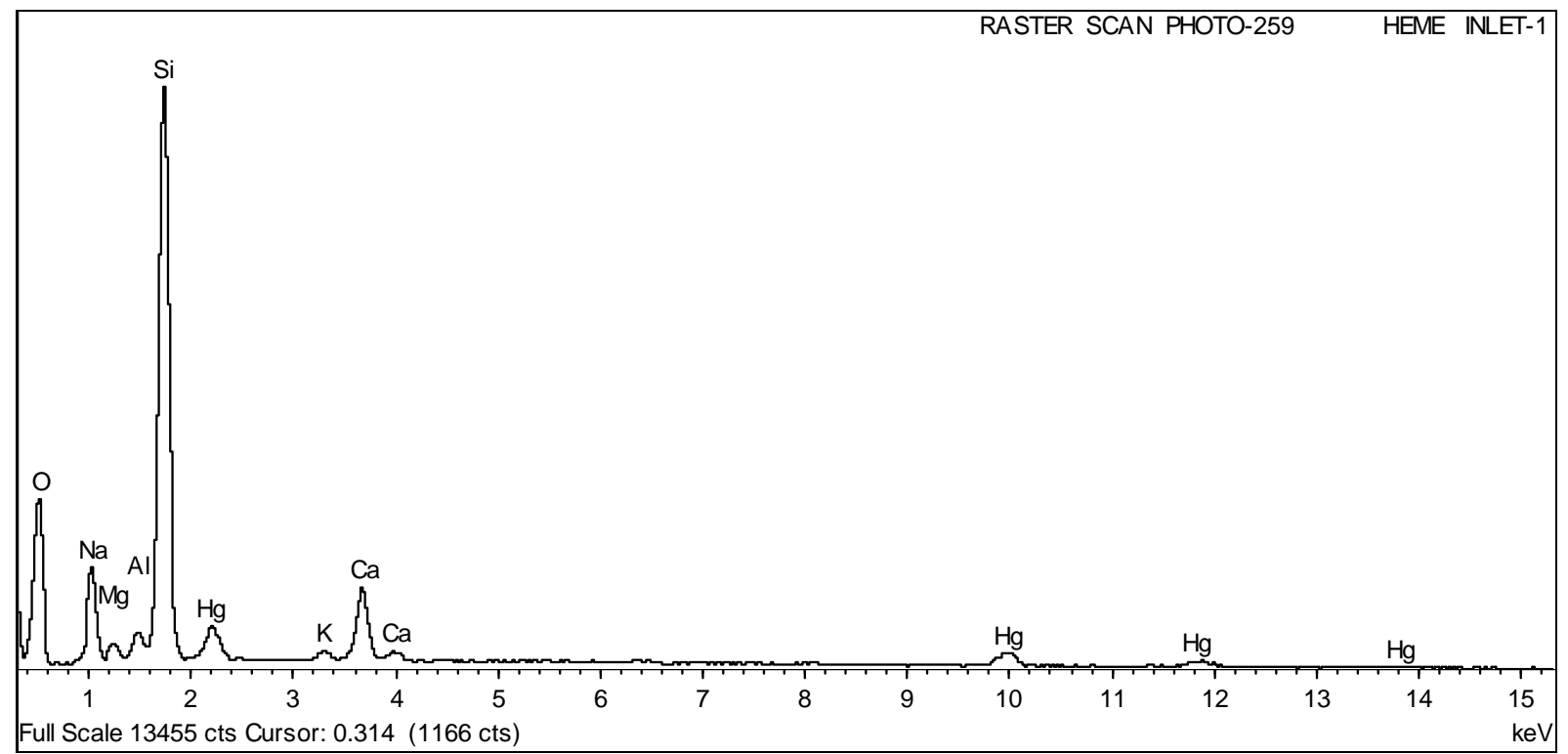

Figure 19. SEM EDX raster scan spectrum of the elements found in the HEME area outlined in Figure 18 


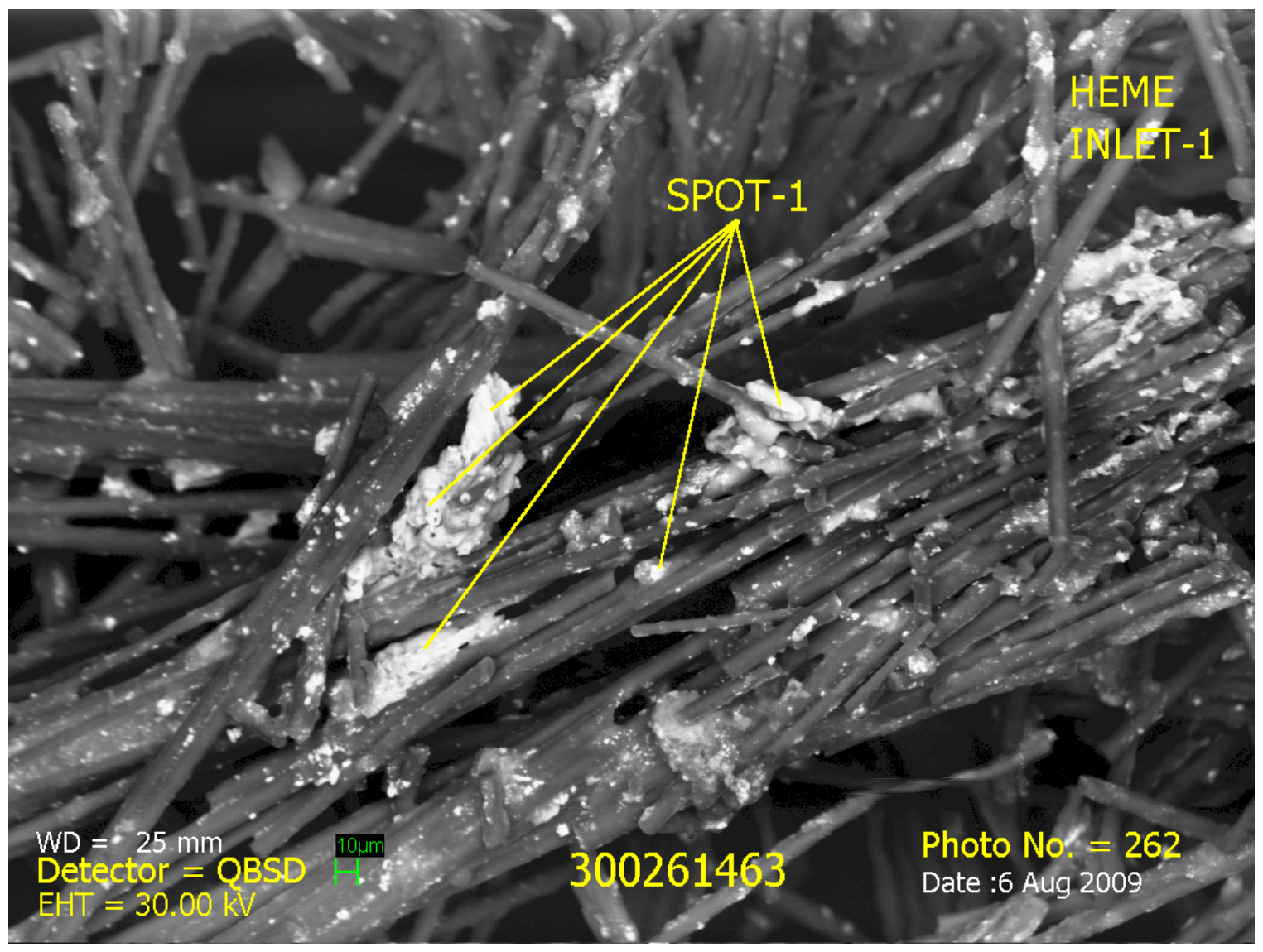

Figure 20. SEM image of DWPF GC Line Filter Assembly HEME, Inlet side, filter media

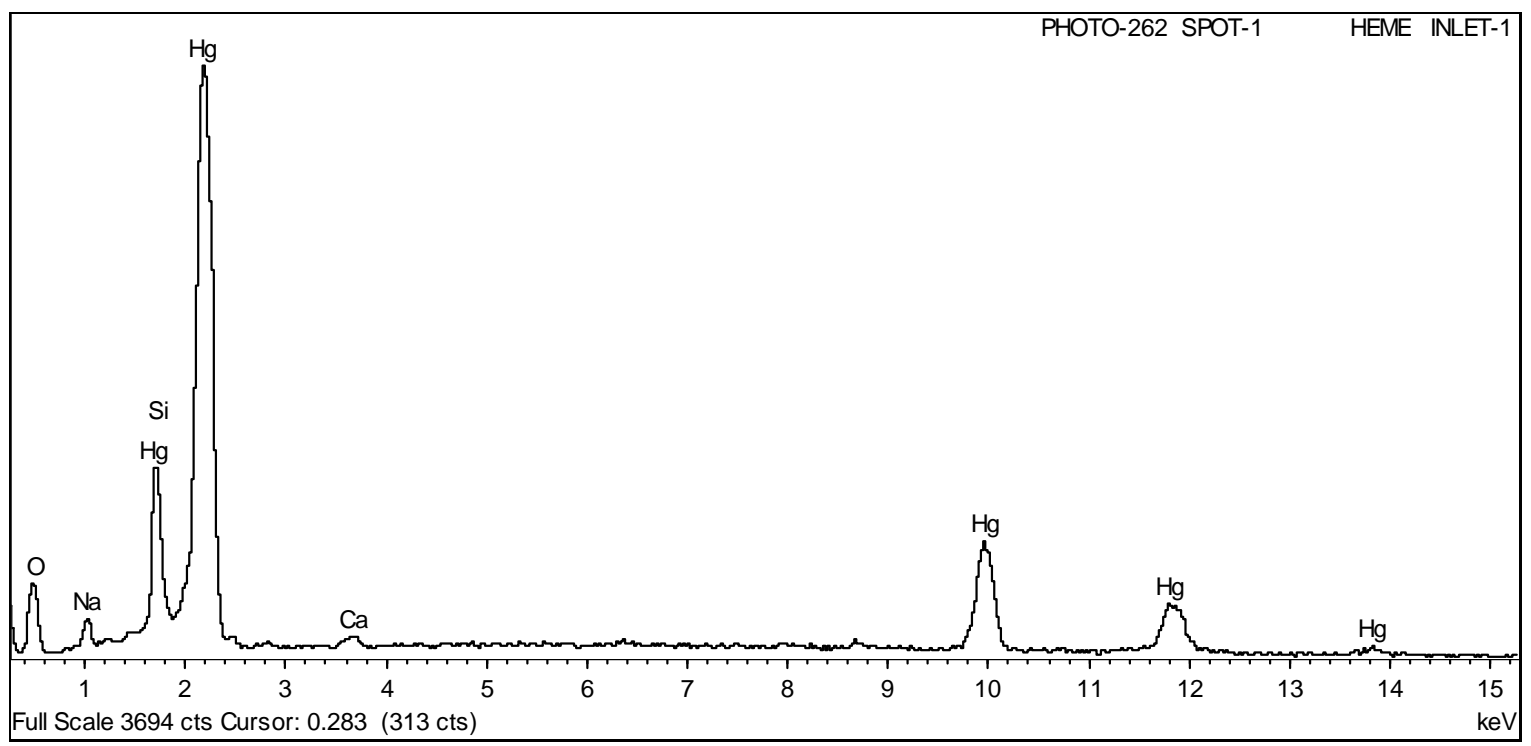

Figure 21. SEM EDX spectrum of the HEME, Spot 1 in Figure 20 


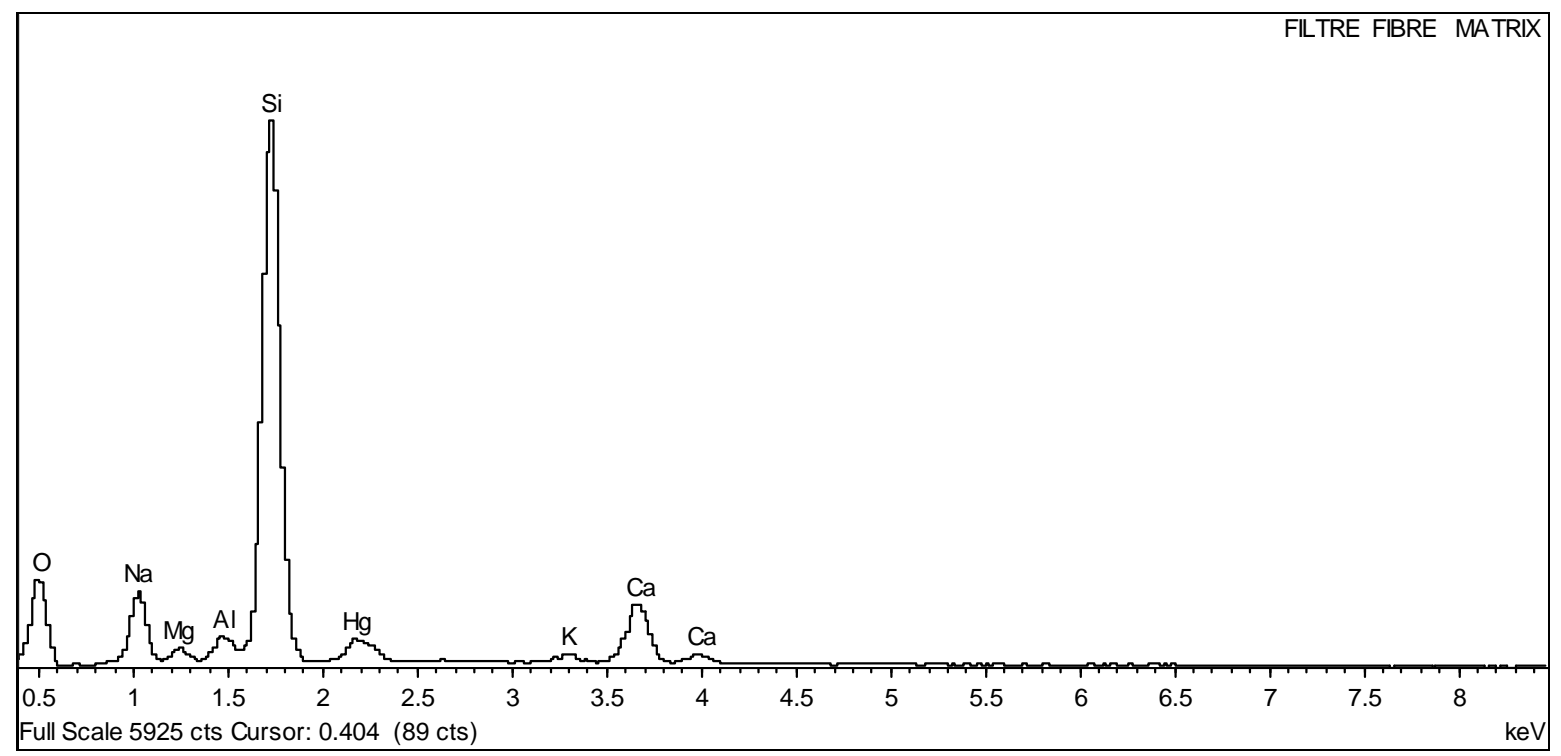

Figure 22. SEM EDX spectrum of the HEME Fiber Matrix in Figure 18

The HEME outlet side raster scan was identical to that obtained for the inlet side. The outlet end of the filter appeared to have even more deposited solids than did the inlet end (refer to Figure 23), which is consistent with the observed solids that were found after the filter media on the outlet side screen and on the surrounding housing walls. There was what appears to be non-Hg containing, trace particulate matter on the filter media, but these did not appear to comprise a significant portion of the deposited solids.

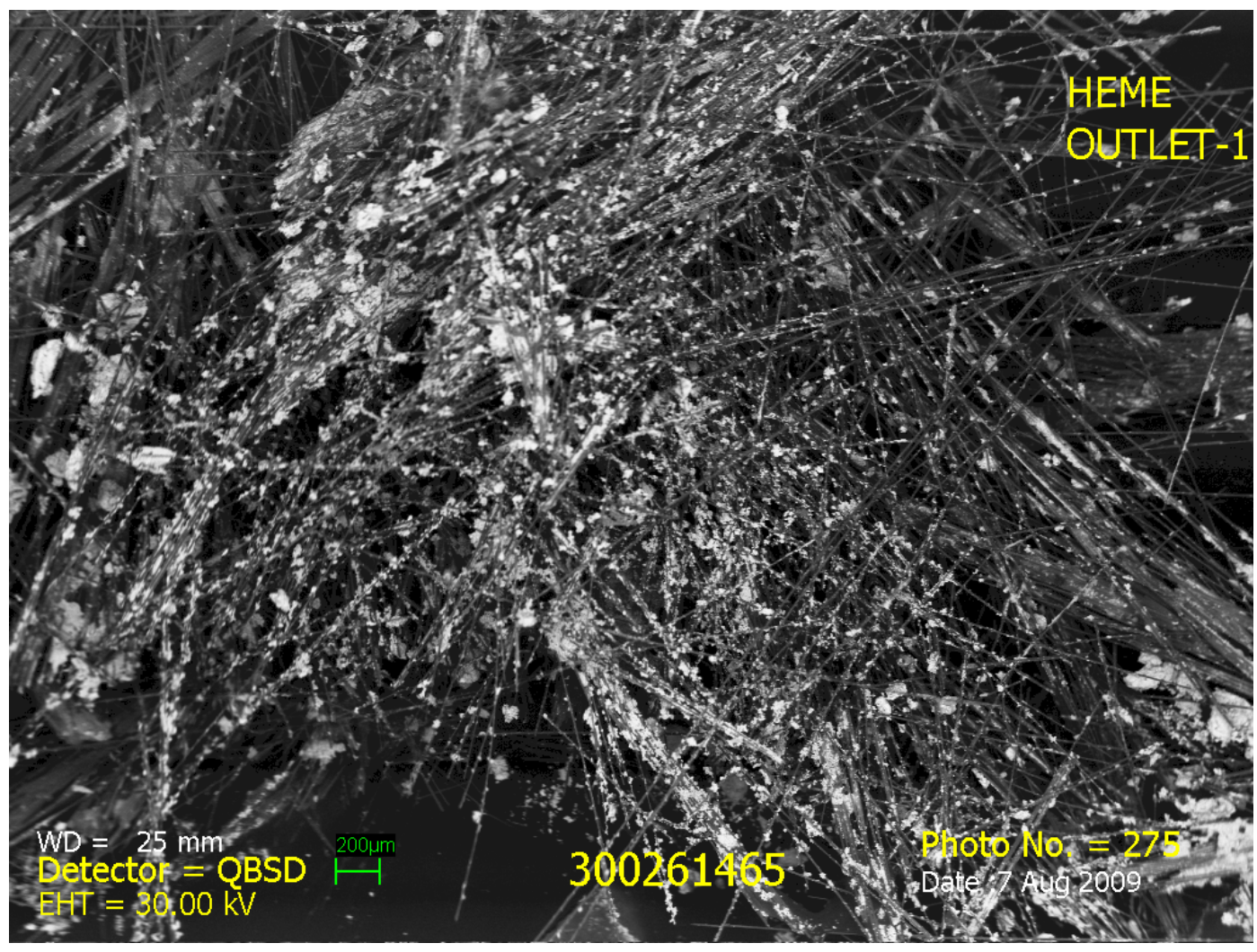

Figure 23. SEM image of DWPF GC Line Filter Assembly HEME, Outlet side, filter media 
The deposited solids, shown in Figure 24, removed from the HEME outlet screen and housing walls were found to contain Hg. The SEM EDX spectrum obtained from this material is given in Figure 25. This material when added to deionized (DI) water did not dissolve, but the material dissolved readily in $0.6 \mathrm{M}$ $\mathrm{HNO}_{3}$ to give a colorless solution.

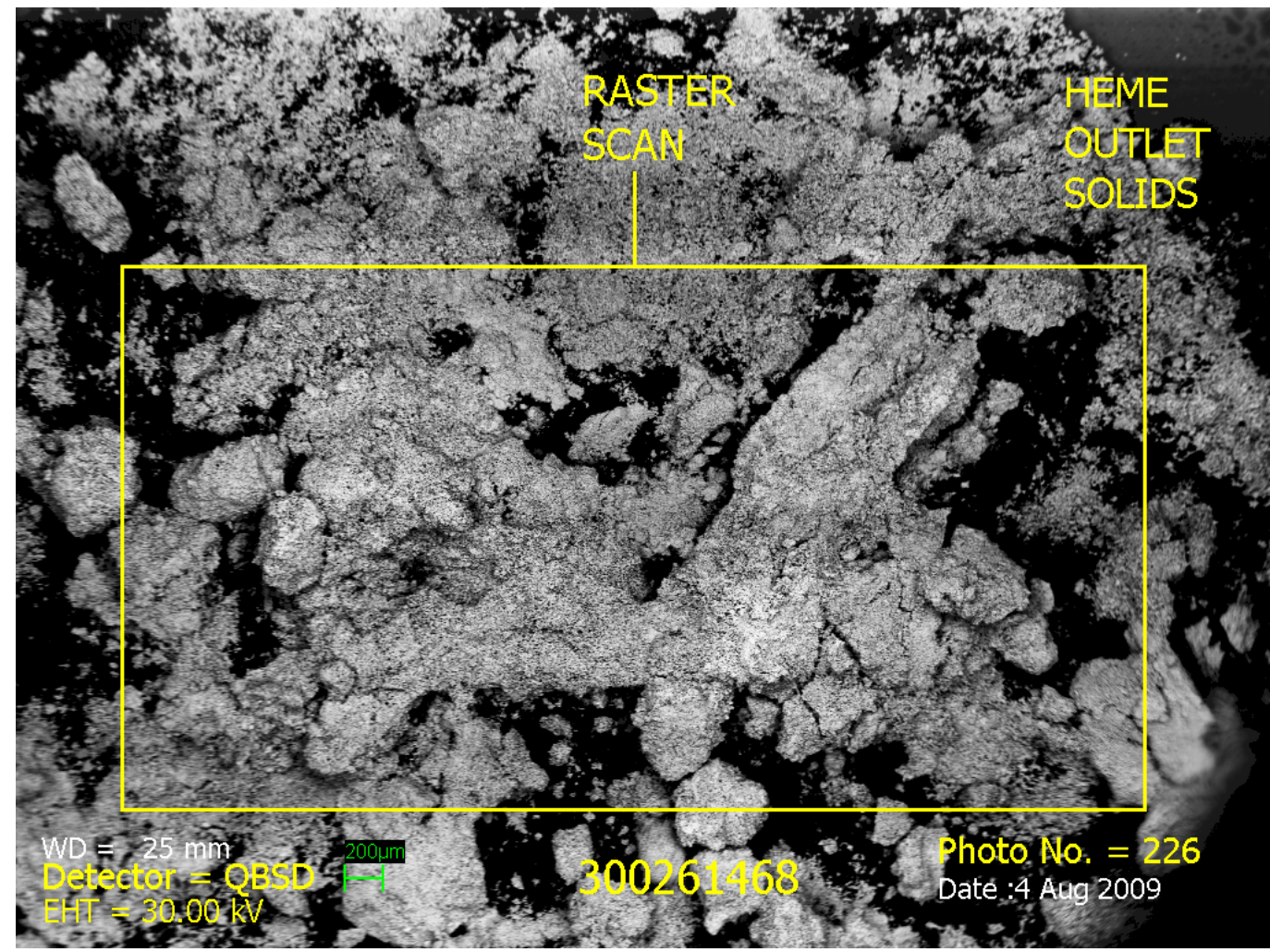

Figure 24. DWPF GC Line Filter Assembly Post-HEME Solids

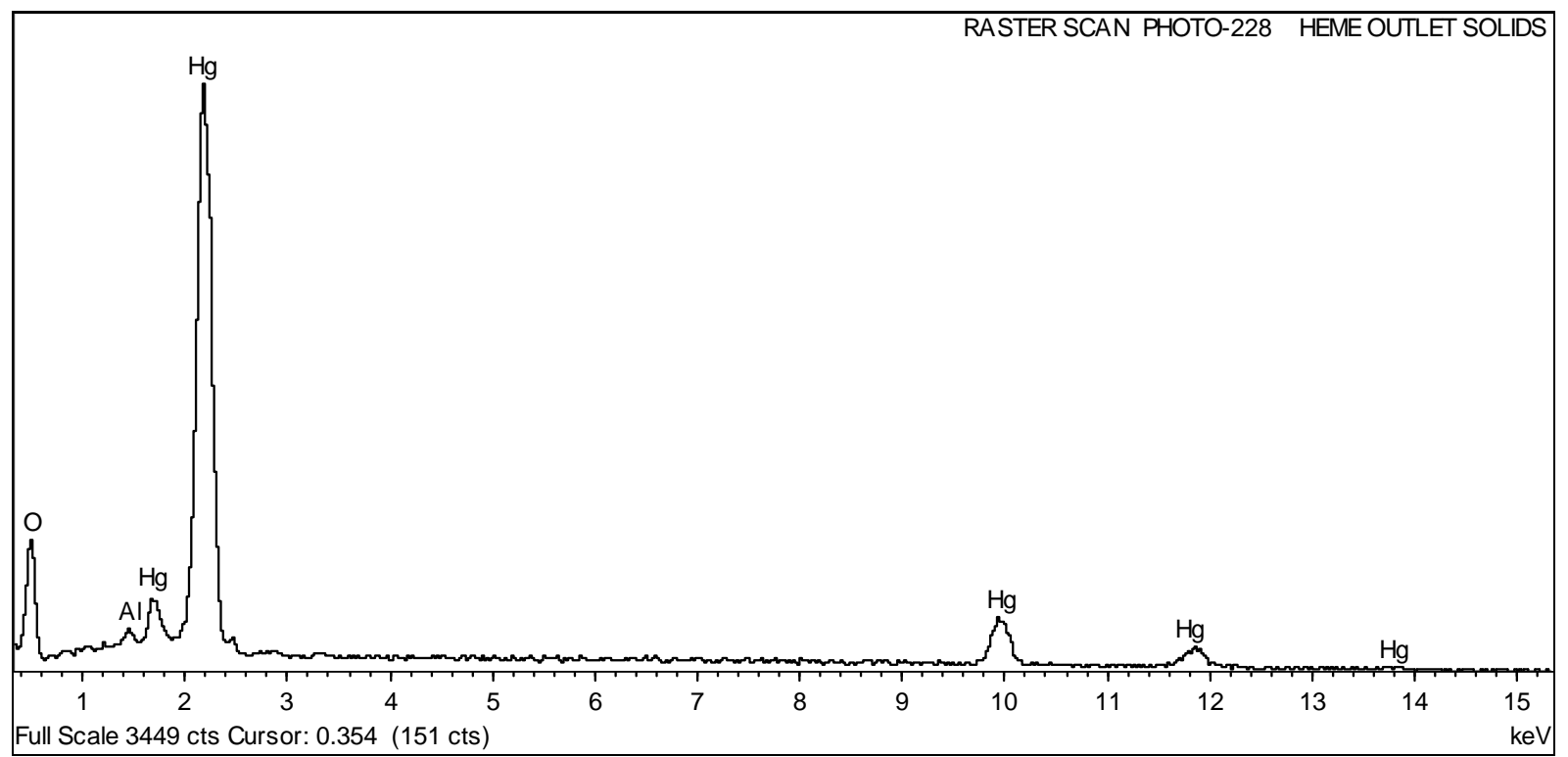

Figure 25. SEM EDX spectrum of the post-HEME solids in Figure 24 


\subsubsection{HEPA-1 Sample Characterization}

The core sample collected from HEPA-1, Figure 26, provides the SEM image for the inlet side HEPA-1 sample with the raster scan area shown in the yellow box.

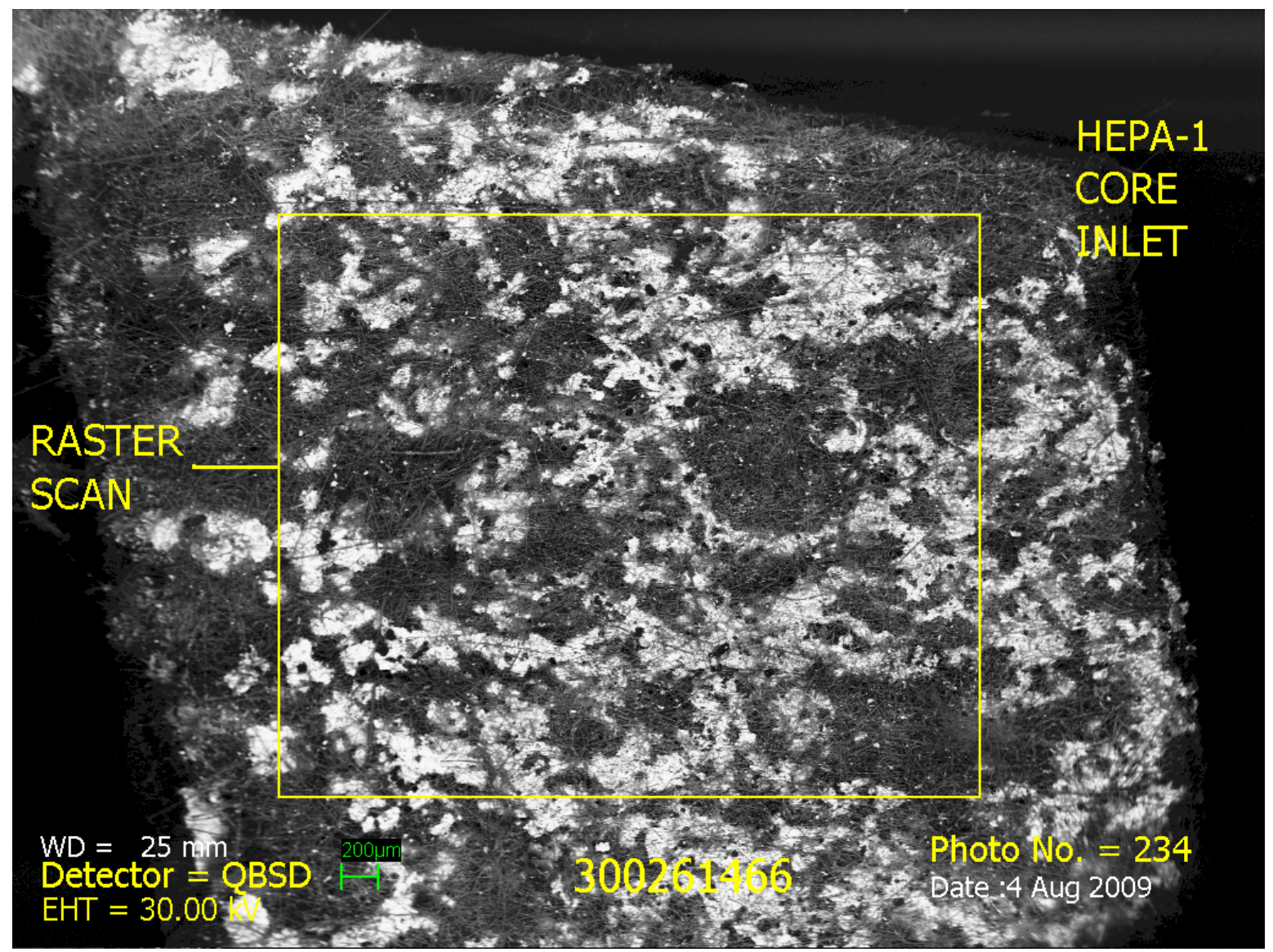

Figure 26. Raster Scan Area of DWPF GC Line Filter Assembly HEPA-1, Inlet Side, Filter Media 


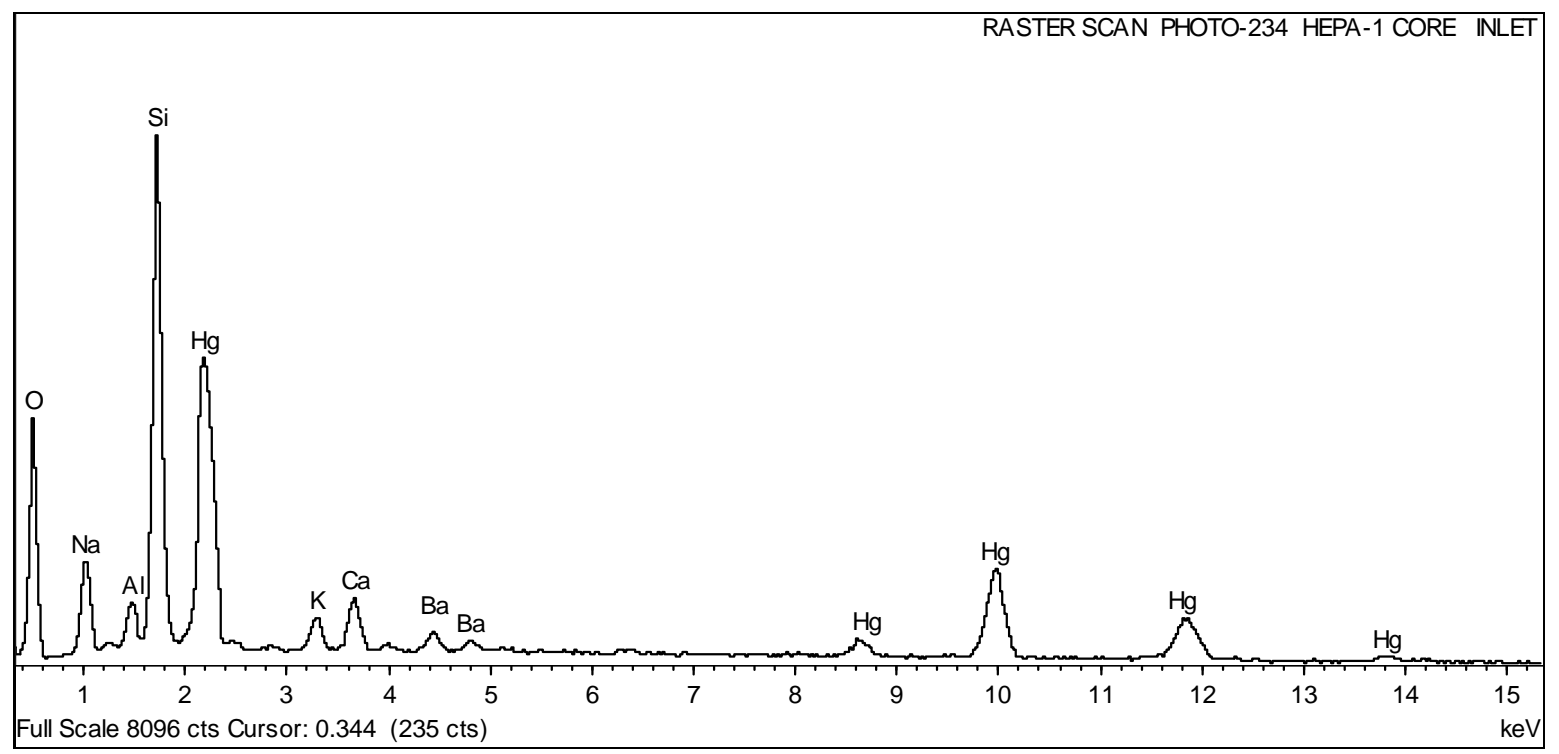

Figure 27. SEM EDX raster scan spectrum of the elements found in the area outlined in Figure 26

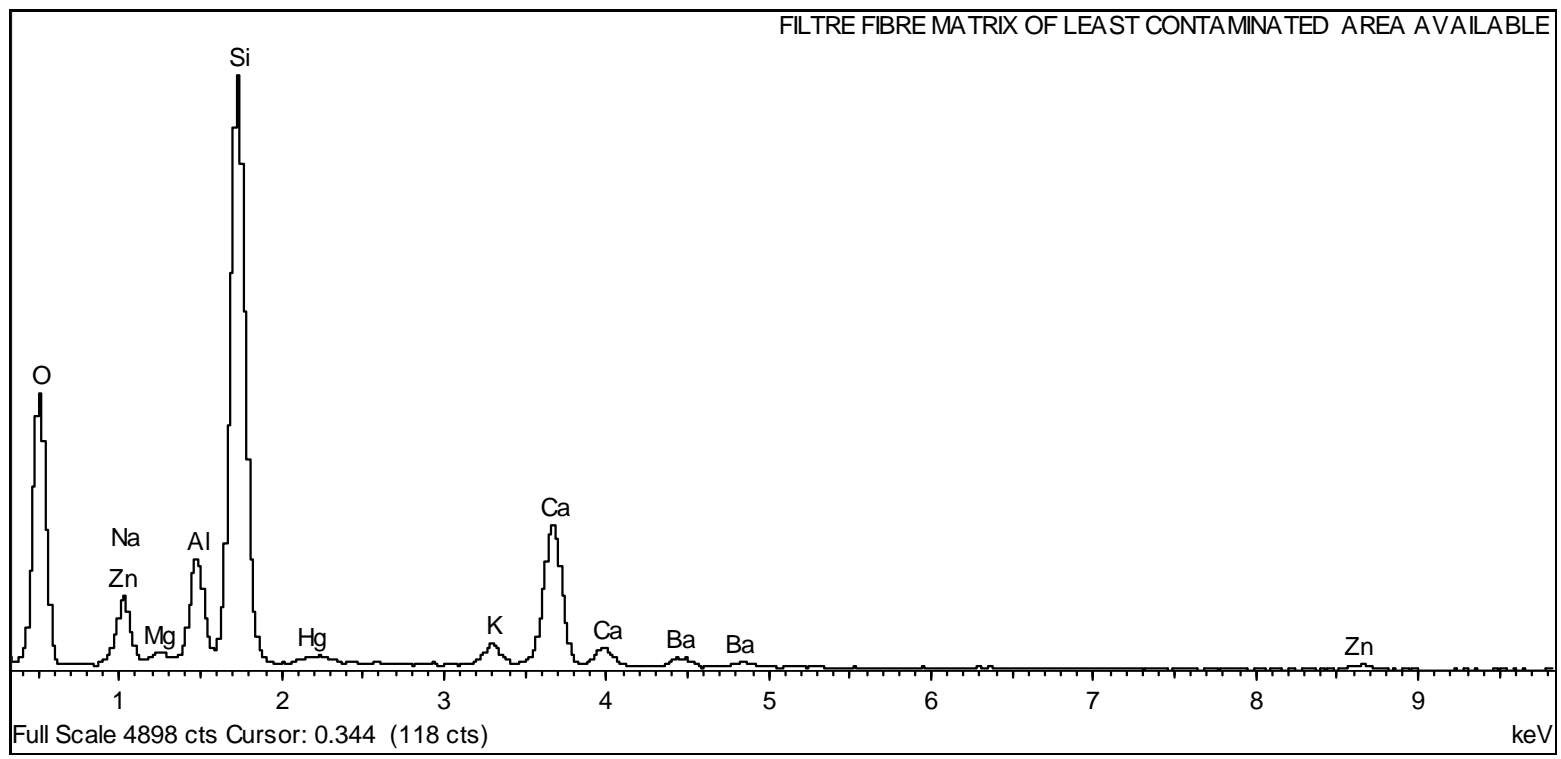

Figure 28. SEM EDX spectrum of the least contaminated area of the filter fiber matrix.

Qualitatively subtracting the spectrum in Figure 28 from that shown in Figure 27, indicates that the primary remaining elements are $\mathrm{Hg}, \mathrm{Na}$, and $\mathrm{O}$. SEM EDX spectrums taken of the spots labeled in Figure 29 indicate that those spots marked with a " 1 " and visible as a white powder in the image are a $\mathrm{Hg}$ containing compound (see Figure 30), while the spots marked with a "2" and visible as dark patches in the image is a $\mathrm{Na}$ and $\mathrm{O}$ containing species. It was not possible to get an exact determination of the $\mathrm{Hg}$ species by SEM due to the volatility of $\mathrm{Hg}$ compounds in the electron beam. 


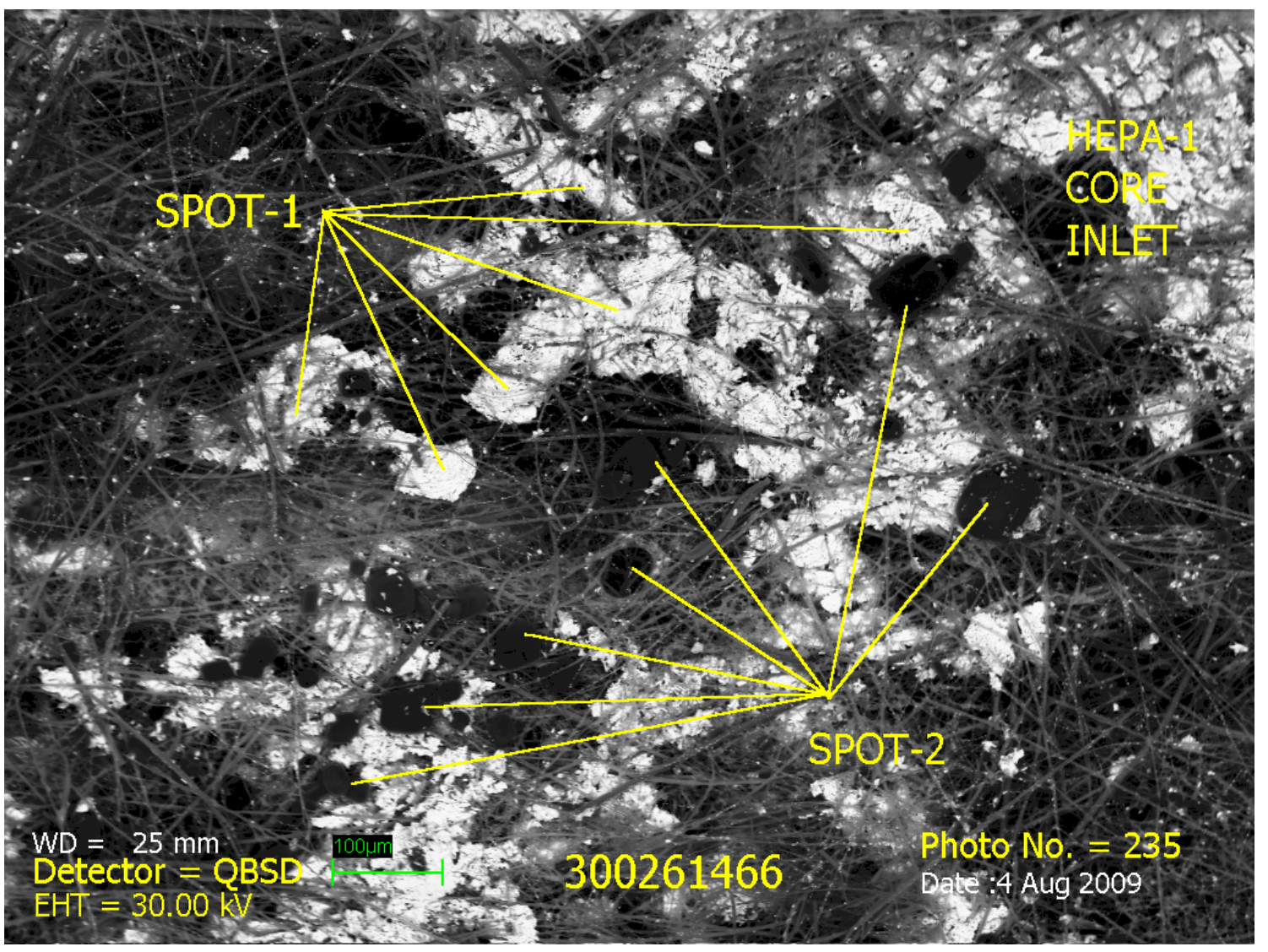

Figure 29. SEM image of DWPF GC Line Filter Assembly HEPA-1, Inlet side, filter media

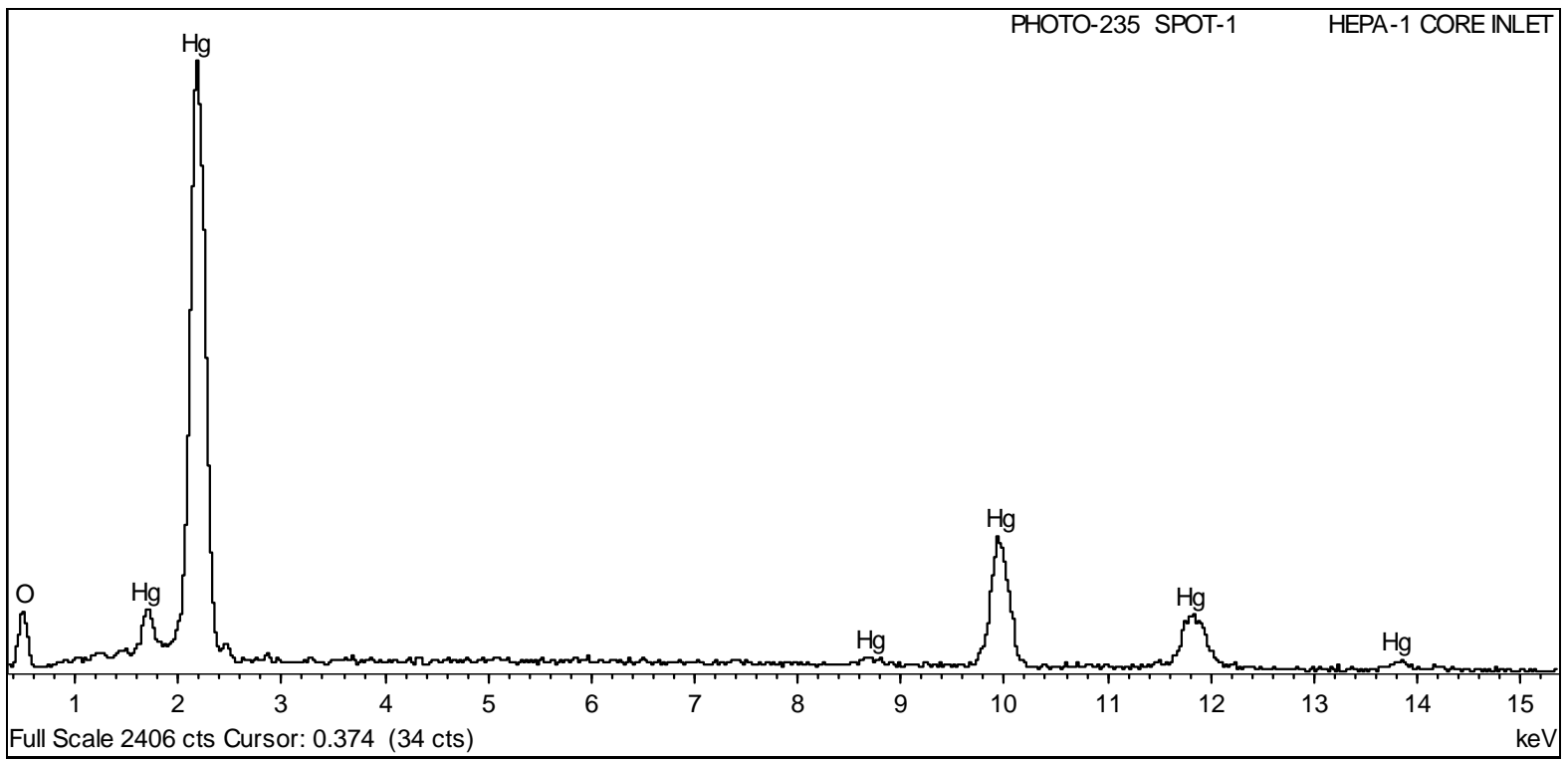

Figure 30. SEM EDX spectrum of HEPA-1, Spot 1 in Figure 29. 
SRNL-STI-2009-00602

Revision 0

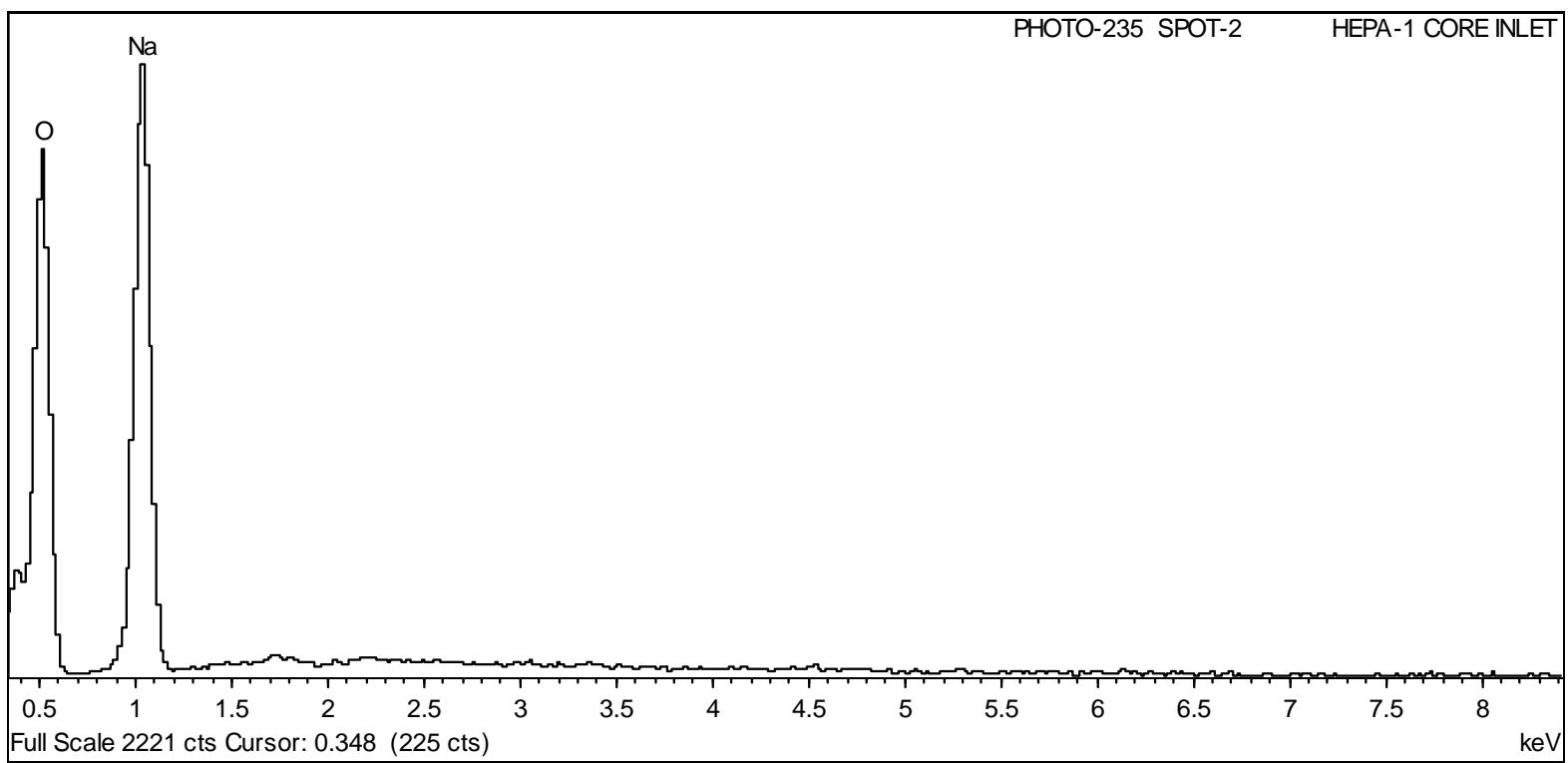

Figure 31. SEM EDX spectrum of HEPA-1, Spot 2 in Figure 29

Similar solids deposits are observed on the HEPA- 1 outlet side filter media, though the extent of Hg contamination appears to be lighter as can be observed by comparing Figure 26 with that shown in Figure 32.

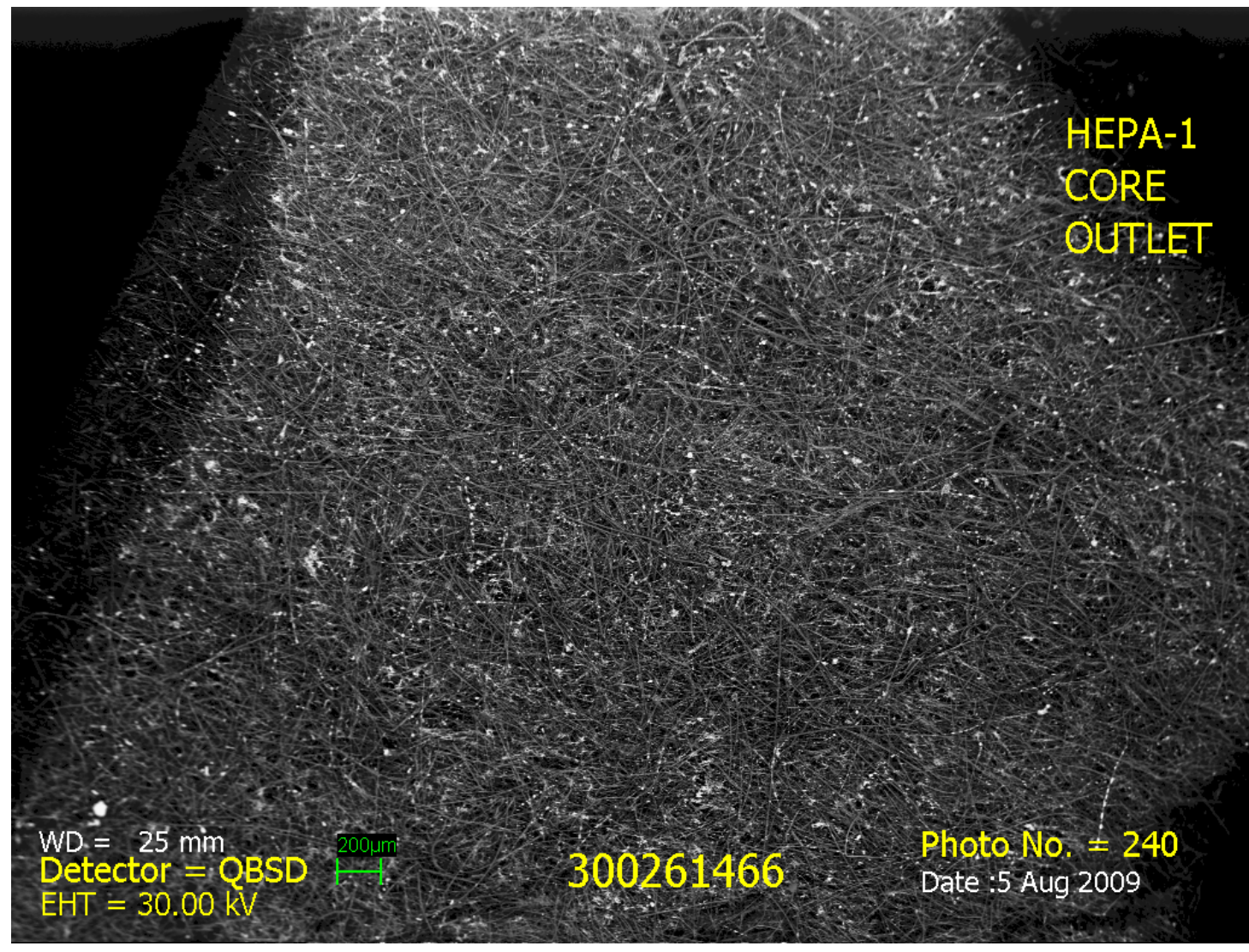

Figure 32. Raster Scan of DWPF GC Line Filter Assembly HEPA-1, Outlet Side, Filter Media 
A closer look at the outlet side filter media of HEPA-1, as seen in Figure 33, shows the same Hg species at spot 2 and an additional $\mathrm{Mg} / \mathrm{Si} / \mathrm{O}$ species at spot 1. The SEM EDX spectrum of this material is shown in Figure 34. The SEM EDX spectrum obtained from the raster scan of the outlet side filter media does not show a significant contribution from $\mathrm{Mg}$, so these particles seem to be of limited distribution relative to the $\mathrm{Hg}$ species seen across the filter.

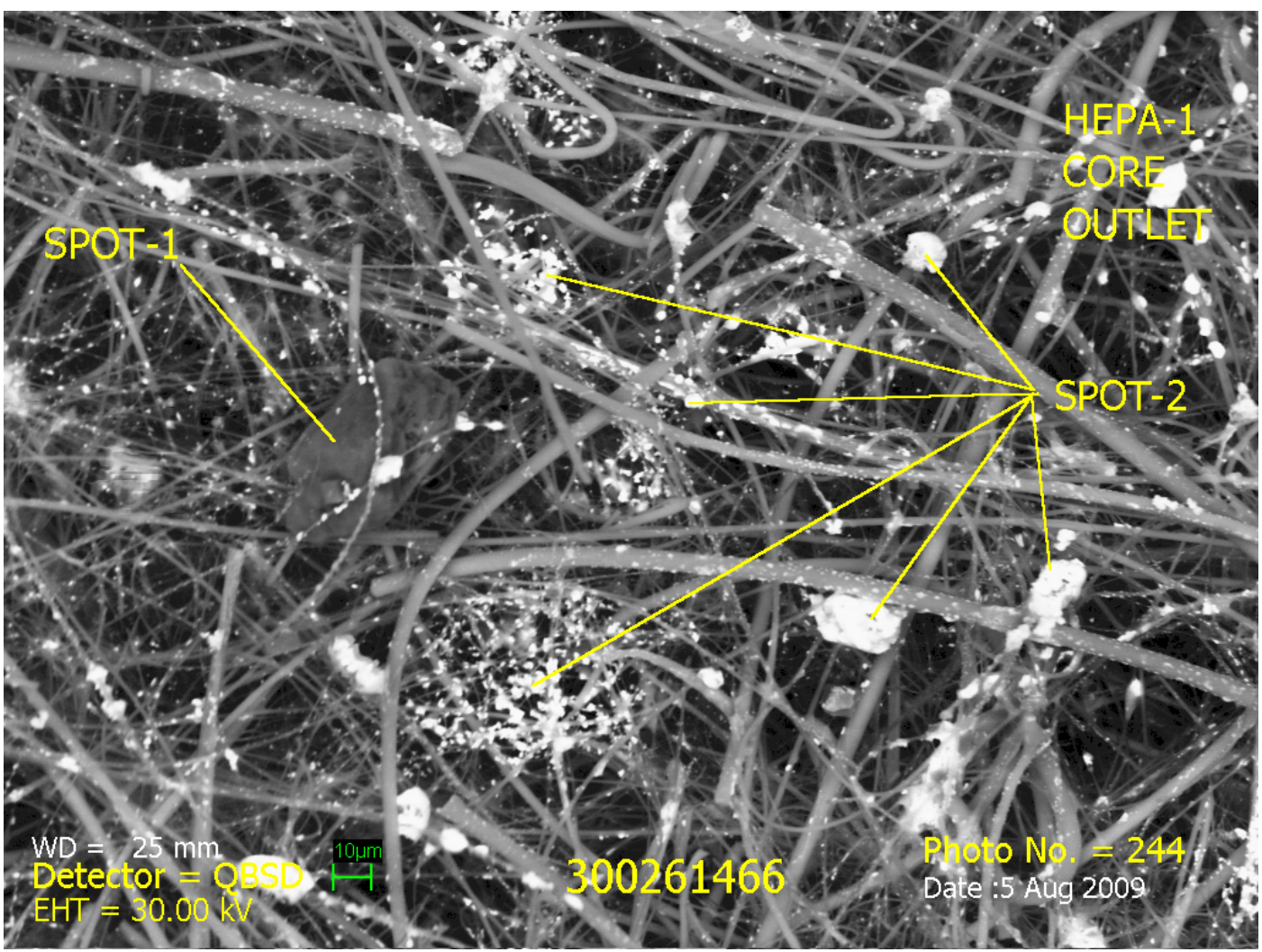

Figure 33. SEM image of DWPF GC Line Filter Assembly HEPA-1, outlet side, filter media

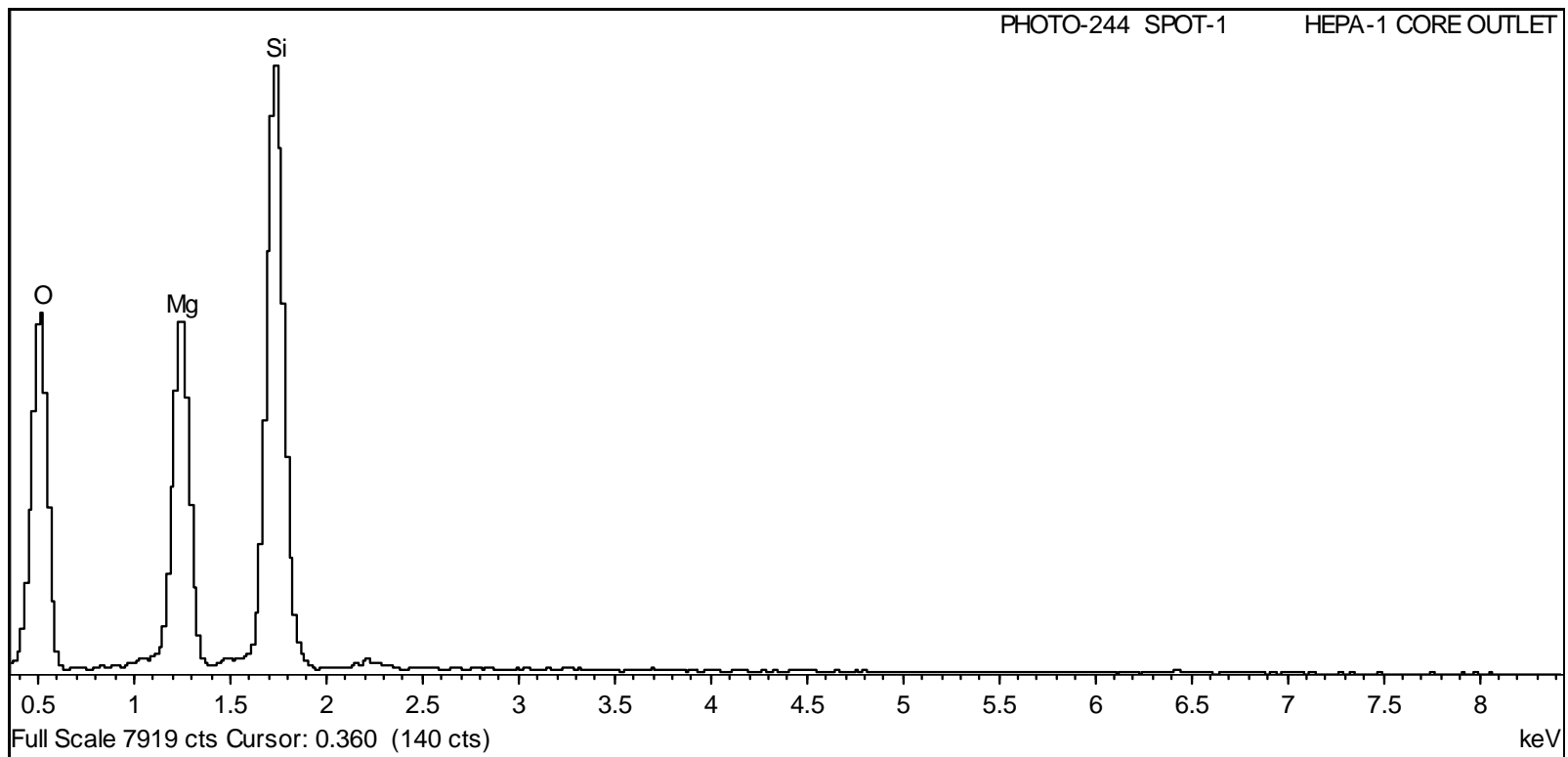

Figure 34. SEM EDX spectrum of HEPA-1, Spot 1 in Figure 33 
SRNL-STI-2009-00602

Revision 0

\subsubsection{HEPA-2 Sample Characterization}

The deposits observed on the HEPA-2 filter media are more evenly distributed throughout the media and not as concentrated on the inlet side. Figure 35 provides the SEM image for the inlet side HEPA-2 sample with the raster scan area shown in the yellow box. The SEM EDX spectrum obtained for the raster scan is provided in Figure 36

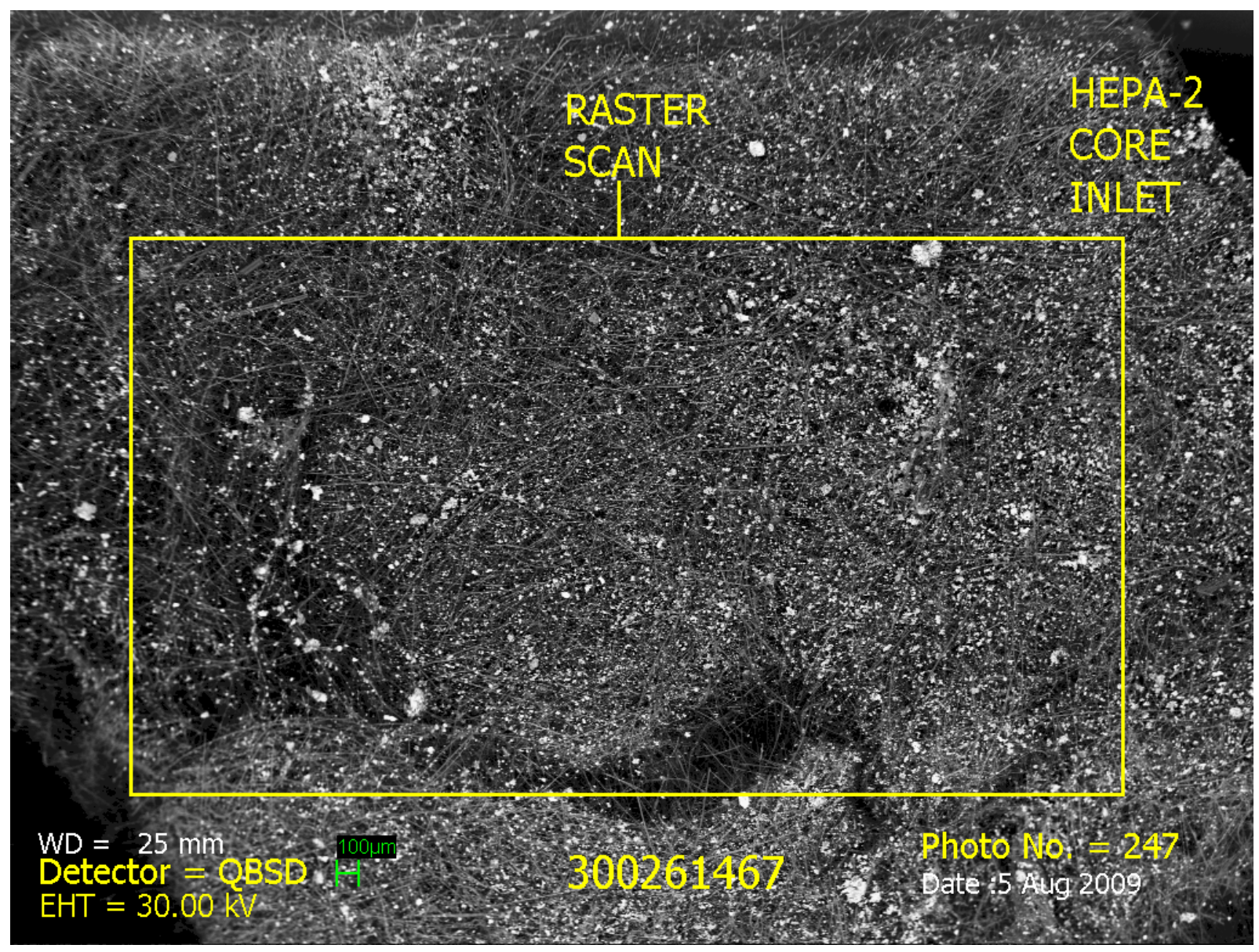

Figure 35. Raster Scan Area of DWPF GC Line Filter Assembly HEPA-2, Inlet Side, Filter Media 


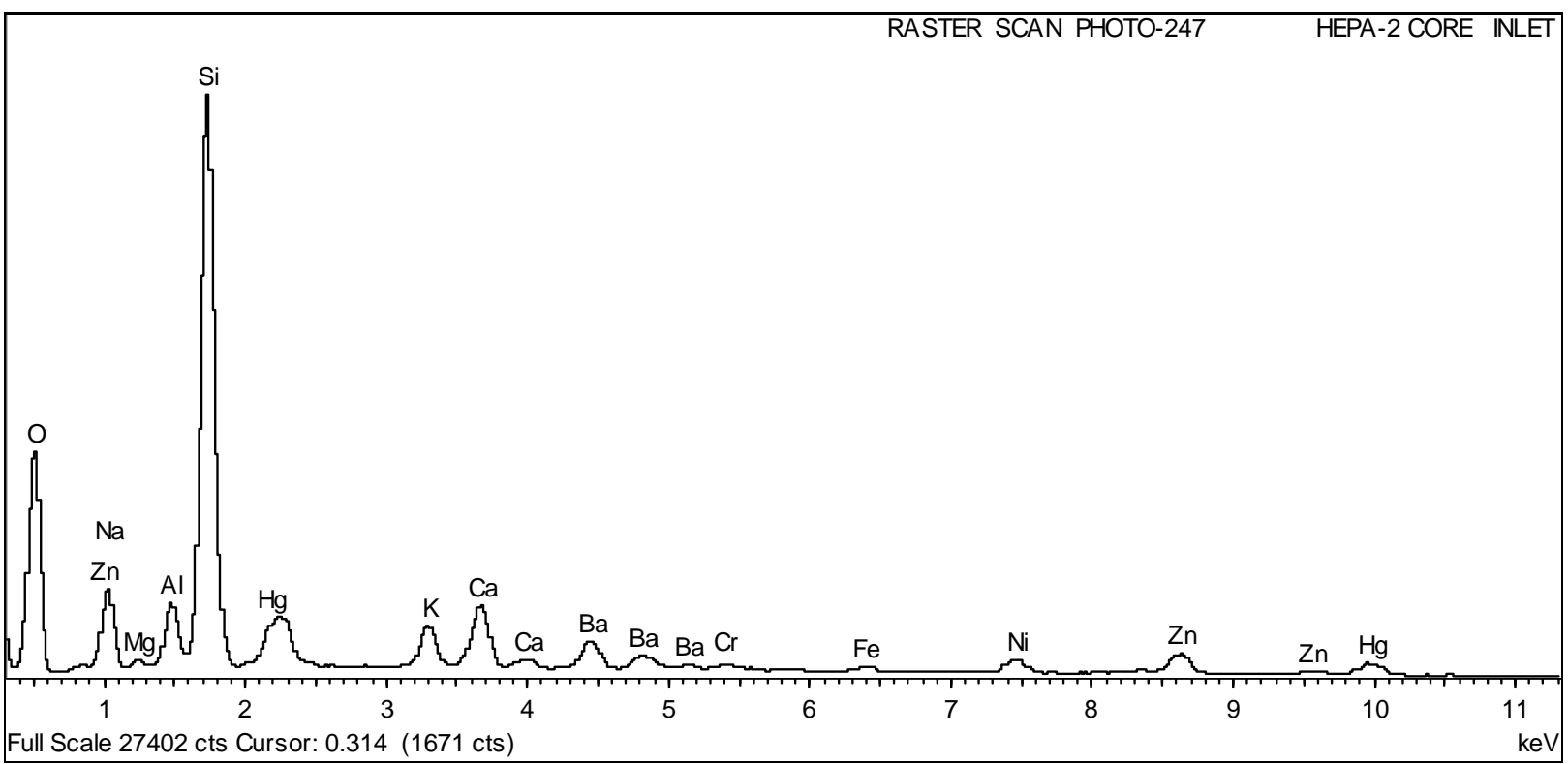

Figure 36. SEM EDX raster scan spectrum of the elements found in the HEPA-2 area outlined in Figure 35

The SEM EDX spectrum shown in Figure 36 is similar to that seen for the HEPA-1 inlet side filter media, but it also shows that several additional first row transition elements, namely $\mathrm{Cr}, \mathrm{Fe}, \mathrm{Ni}, \mathrm{Ti}$, and $\mathrm{Zn}$, are present in the sample. A closer look for these materials provided the spectra and analyses shown in Figure 37 through Figure 44. Some of the particles seem to be aggregate solids indicating they may have solidified on the filter together from the gas stream. Analysis of a number of particles designated as Spot 2 in Figure 37, indicates the Hg containing species (see also Figure 45) is also prevalent in HEPA-2. Spot 1 in Figure 37 indicates the presences of a Ti species while Spot 4 in Figure 41 indicates the presence of a $\mathrm{Pb}$ species in addition to the $\mathrm{Hg}$ species observed throughout all the samples. It was not possible to determine how common either the $\mathrm{Ti}$ or $\mathrm{Pb}$ species are in the filter media, but since $\mathrm{Ti}$ and $\mathrm{Pb}$ did not show up in the raster scan analysis of HEPA-2 as given in Figure 36, it is probably safe to assume that they are minor components. 


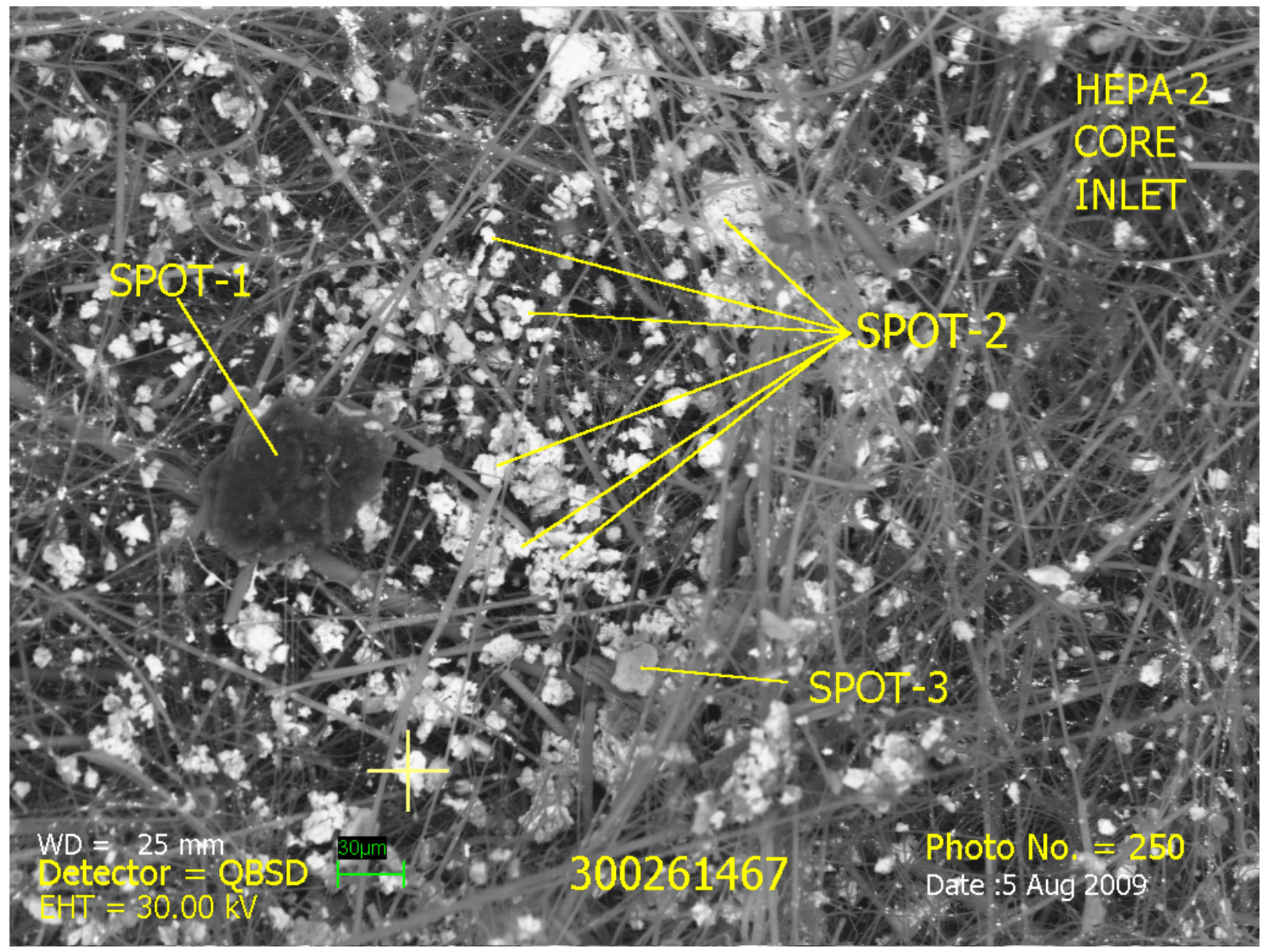

Figure 37. SEM image of DWPF GC Line Filter Assembly HEPA-2, Inlet side, filter media

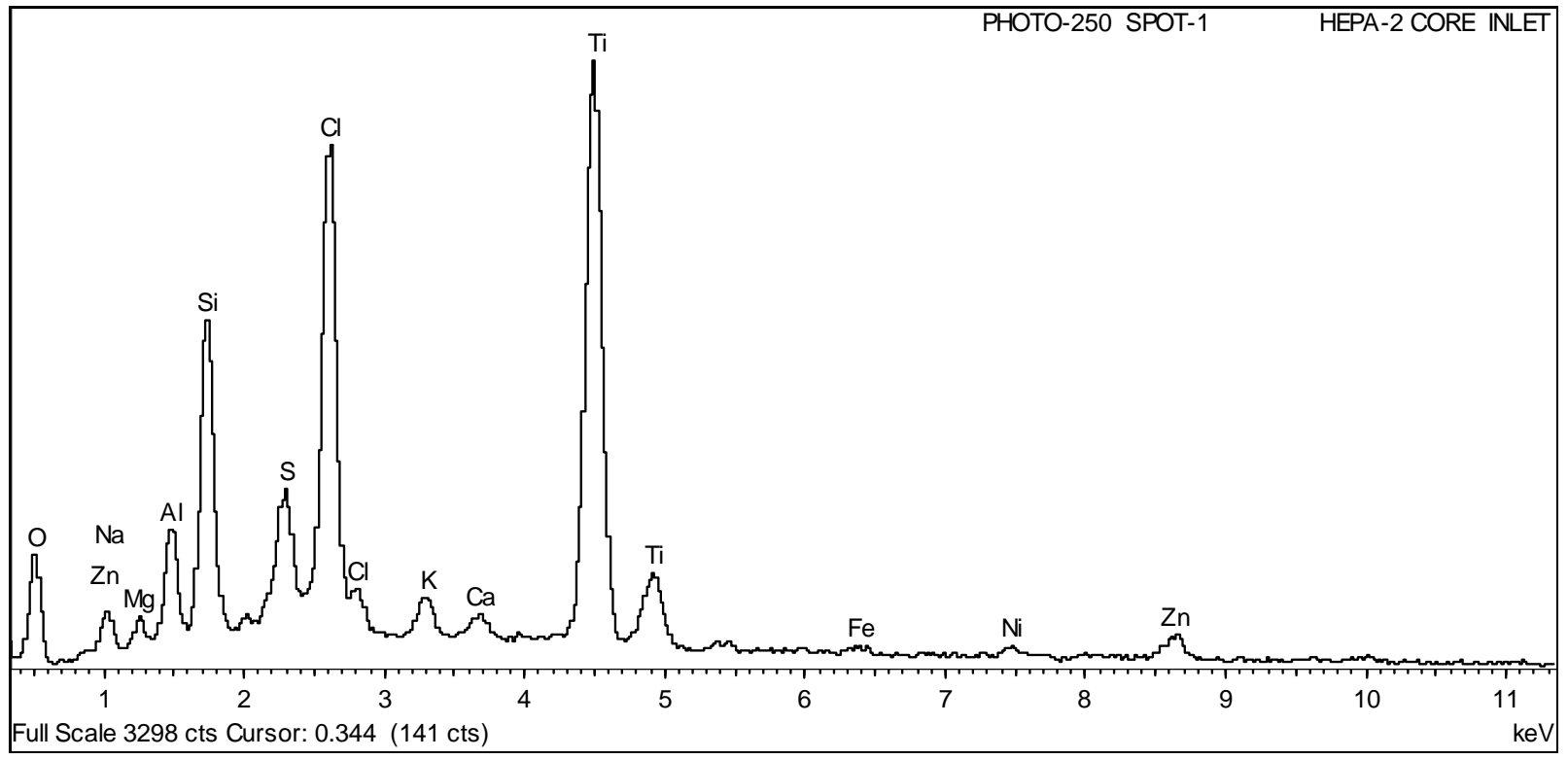

Figure 38. SEM EDX spectrum of HEPA-2, Spot 1 in Figure 37 
SRNL-STI-2009-00602

Revision 0

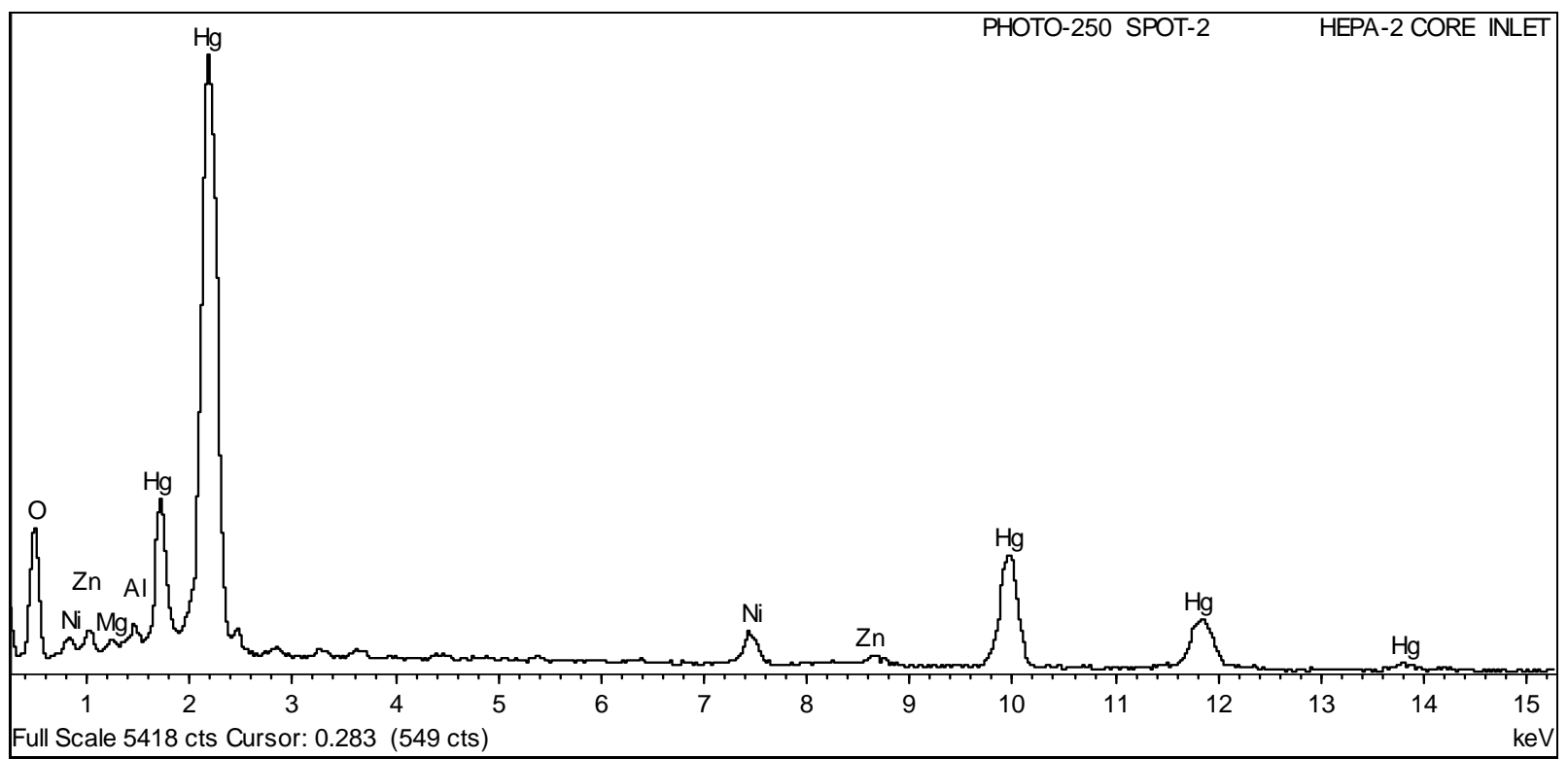

Figure 39. SEM EDX spectrum of HEPA-2, Spot 2 in Figure 37

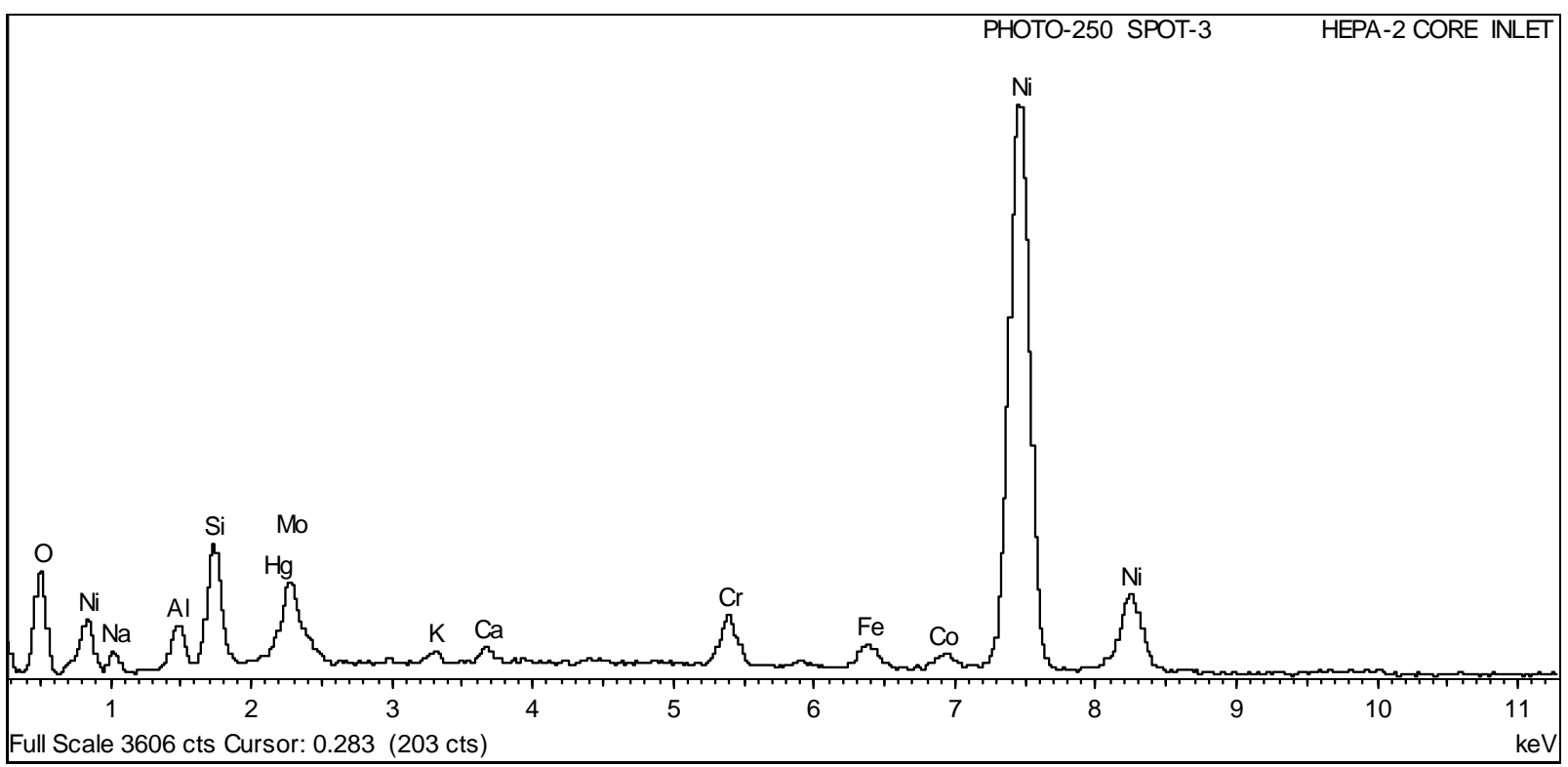

Figure 40. SEM EDX spectrum of HEPA-2, Spot 3 in Figure 37 


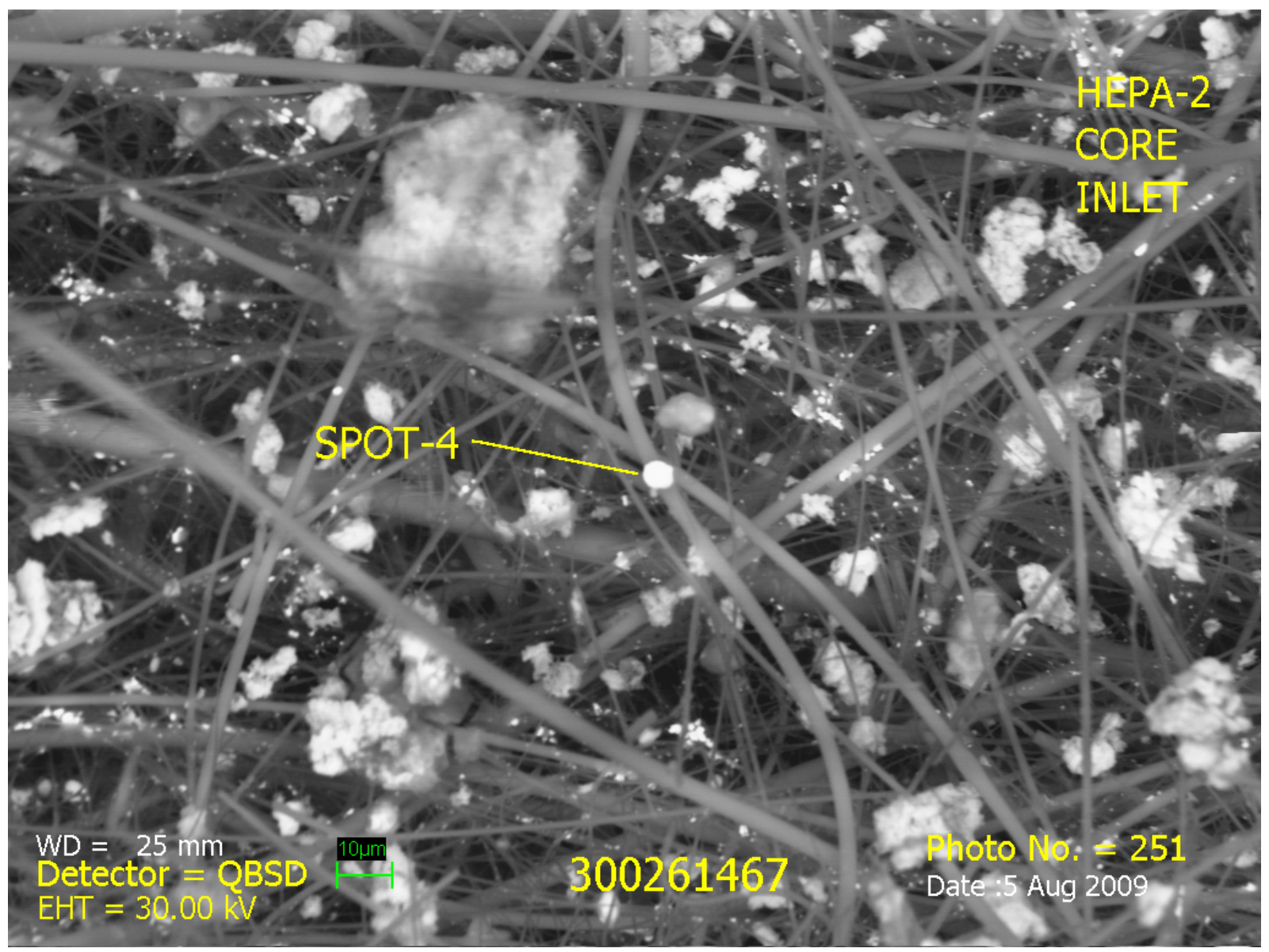

Figure 41. SEM image of DWPF GC Line Filter Assembly HEPA-2, Inlet side, filter media

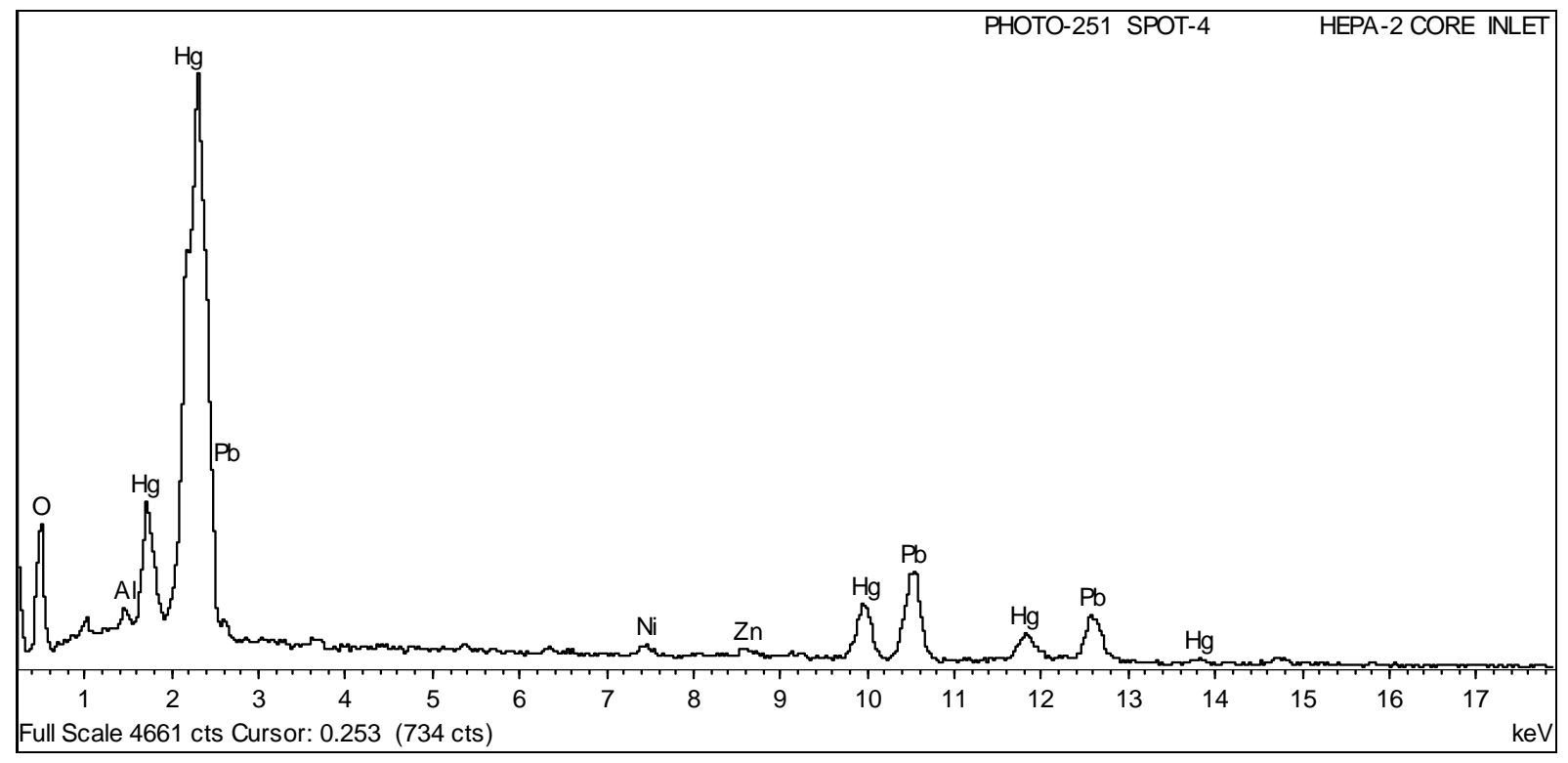

Figure 42. SEM EDX spectrum of HEPA-2, Spot 4 in Figure 41 


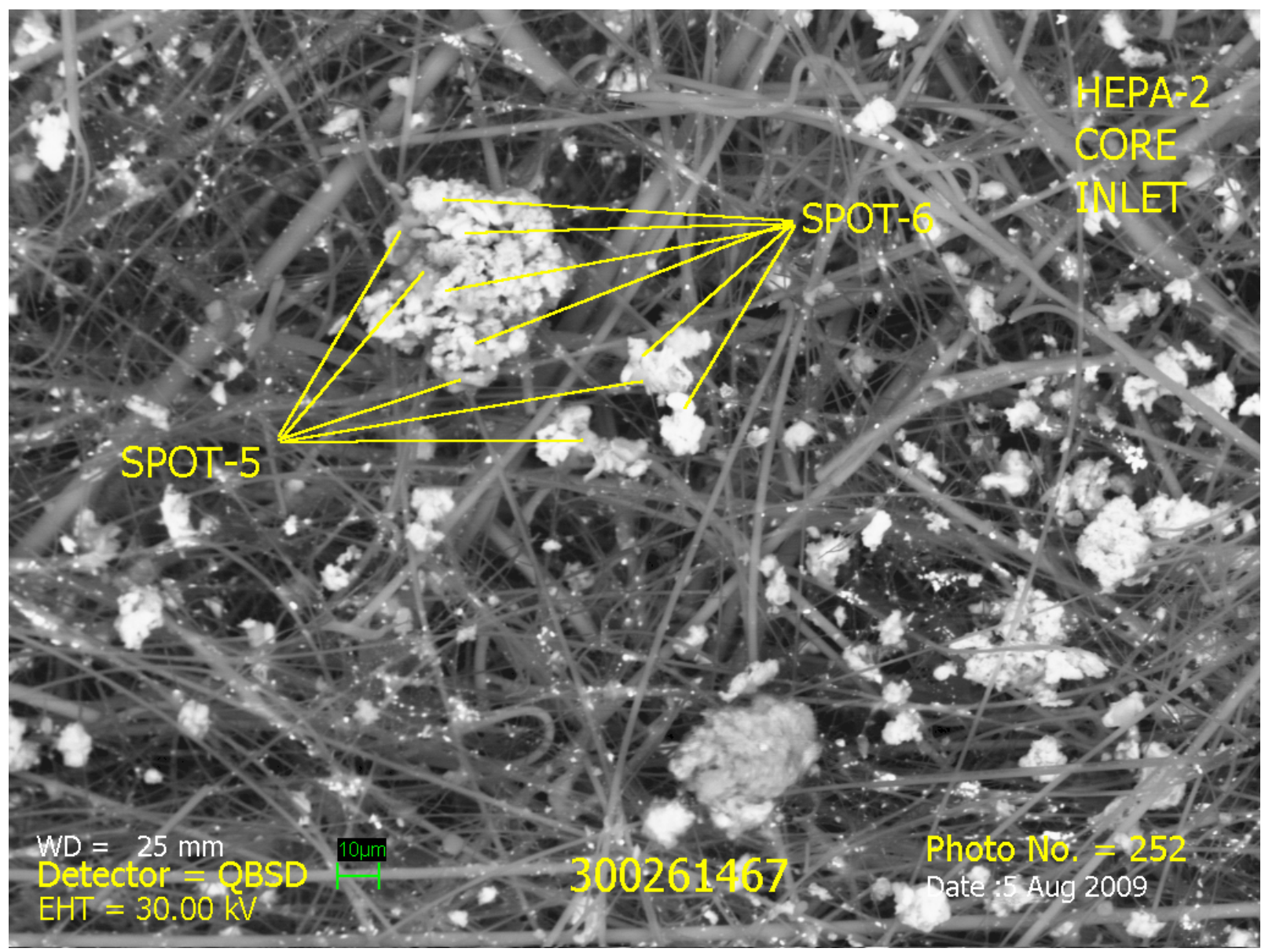

Figure 43. SEM image of DWPF GC Line Filter Assembly HEPA-2, Inlet side, filter media

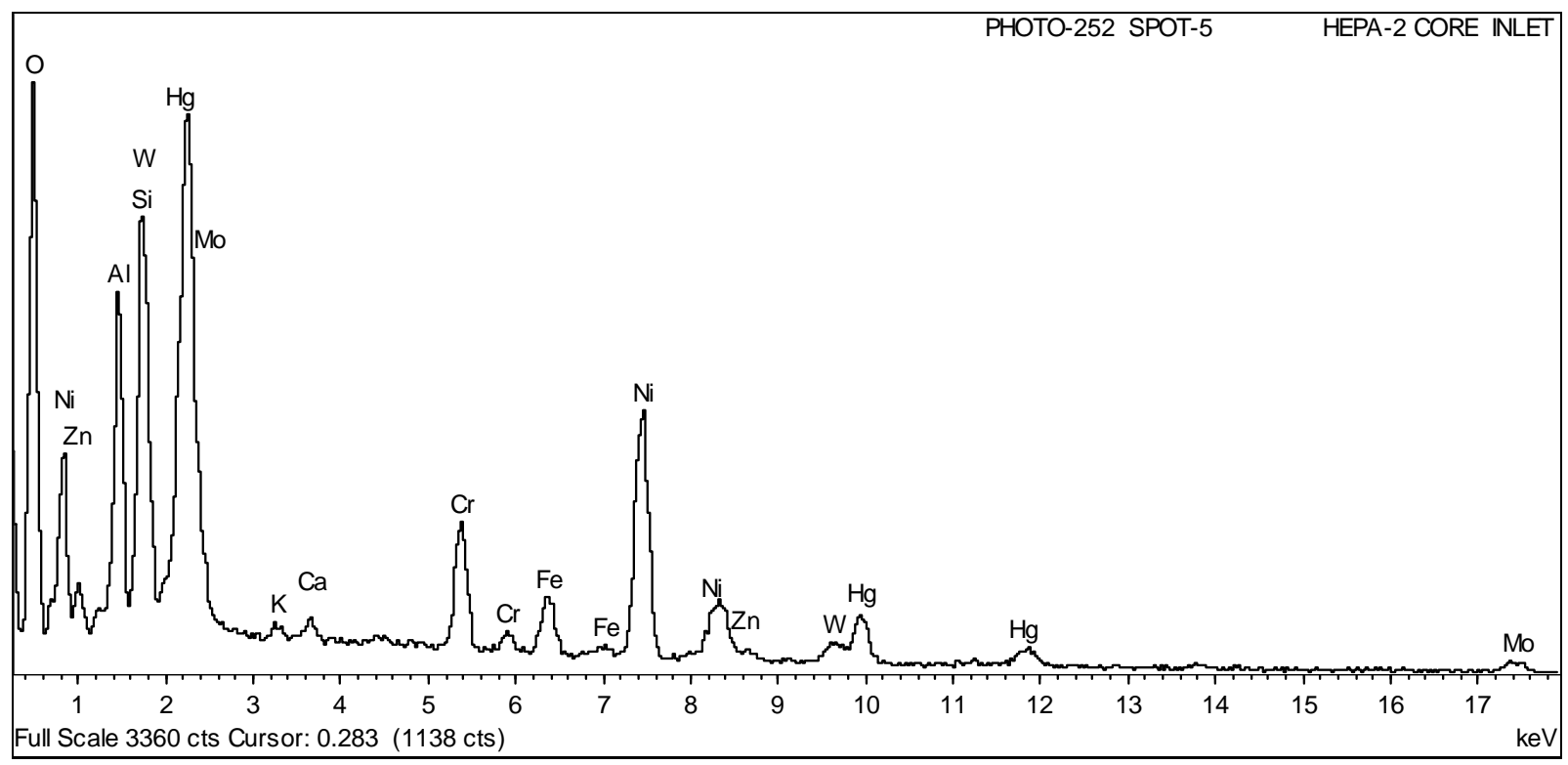

Figure 44. SEM EDX spectrum of HEPA-2, Spot 5 in Figure 43 
SRNL-STI-2009-00602

Revision 0

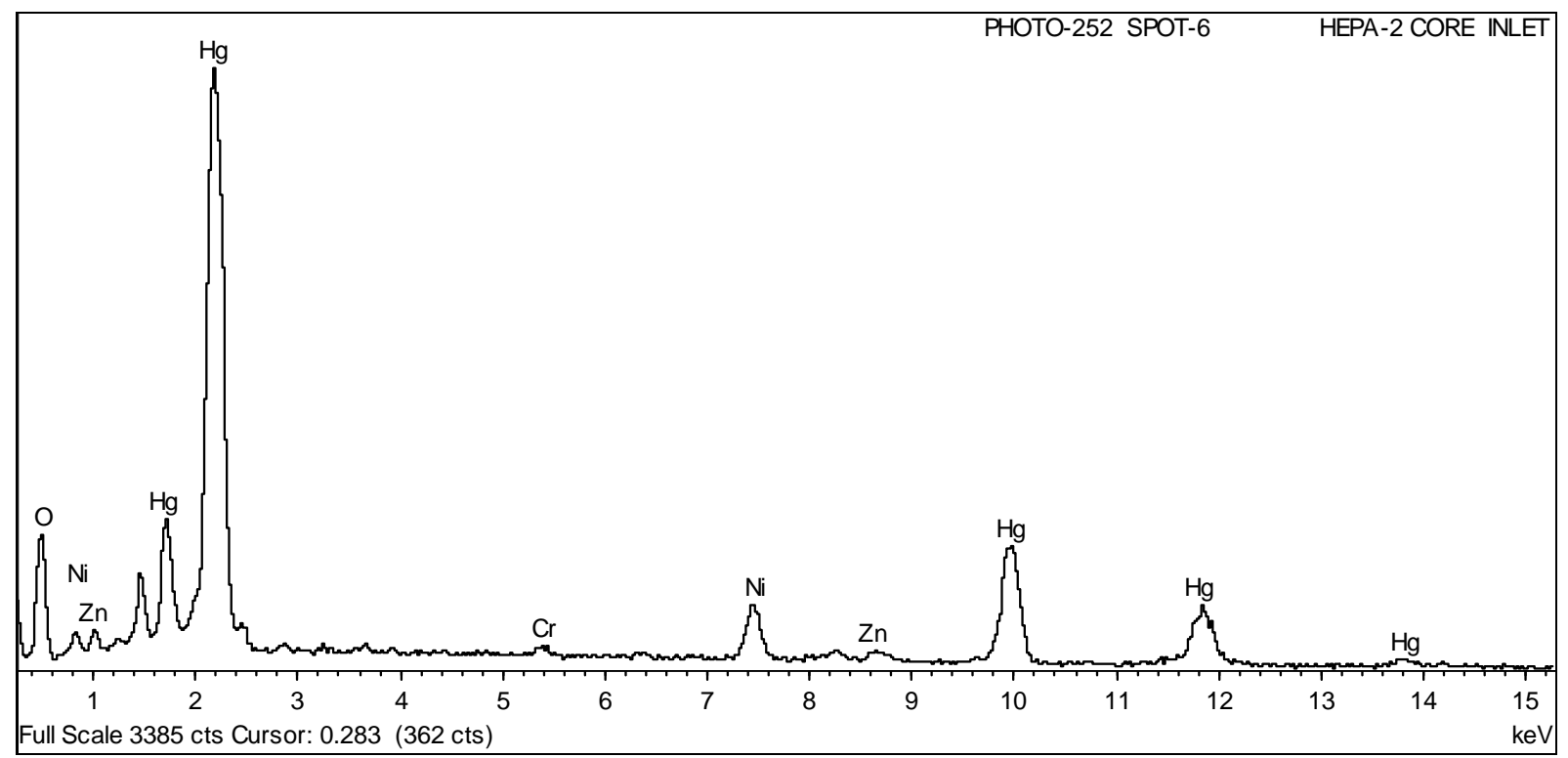

Figure 45. SEM EDX spectrum of HEPA-2, Spot 6 in Figure 43

A raster scan of the outlet end of HEPA-2 is given in Figure 46 and generally reveals the similar list of elements (see Figure 47, Spots 2 -4) found on the inlet side with the exception of the areas indicated by Spot 1 (Figure 48). This spot revealed a F containing material not previously observed; but again, since F does not show up in the raster scan, it is unlikely that this material contributed significantly to the overall particle contamination in the HEPA-2 component. 


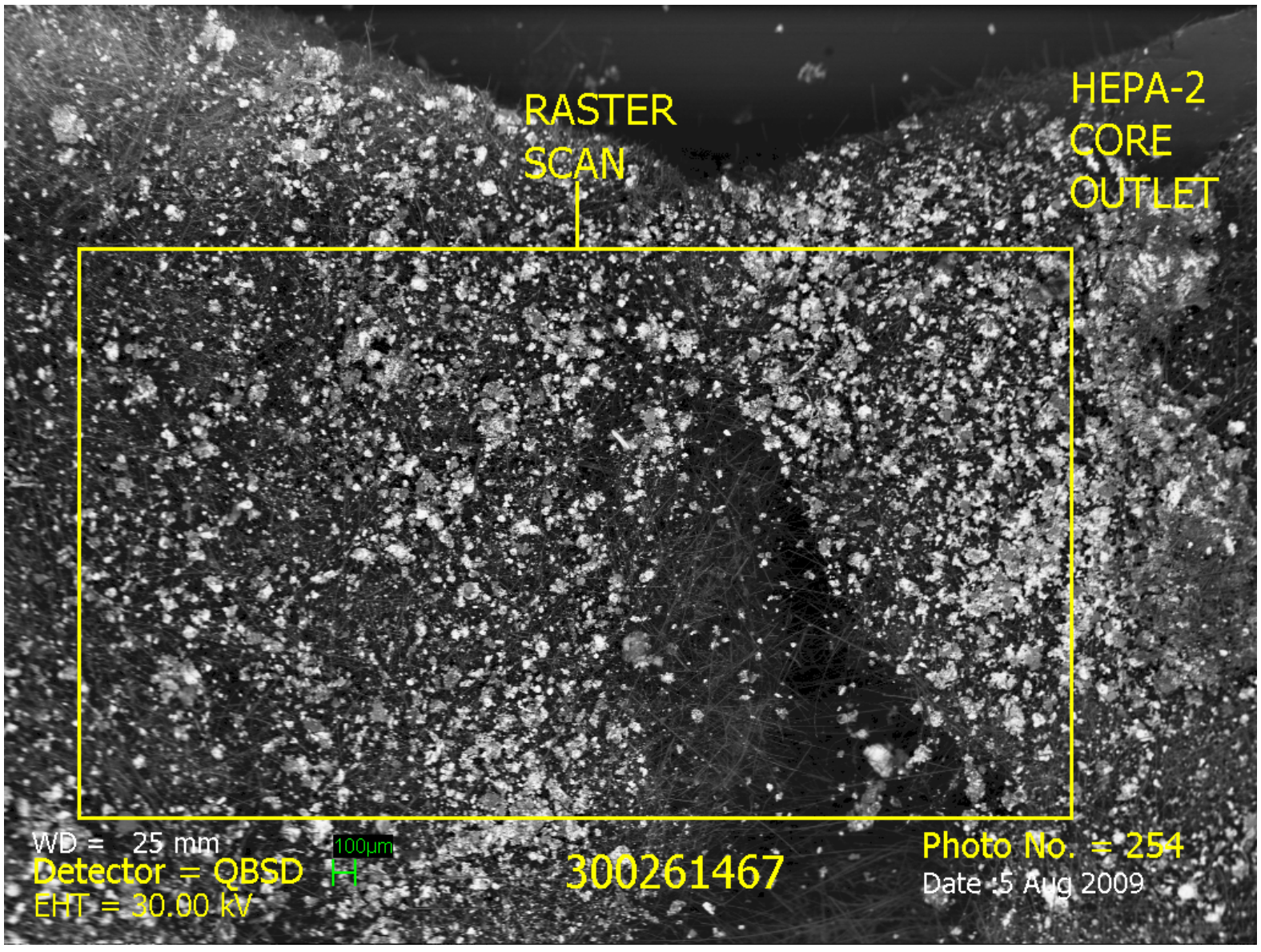

Figure 46. Raster Scan Area of DWPF GC Line Filter Assembly HEPA-2, Outlet Side, Filter Media

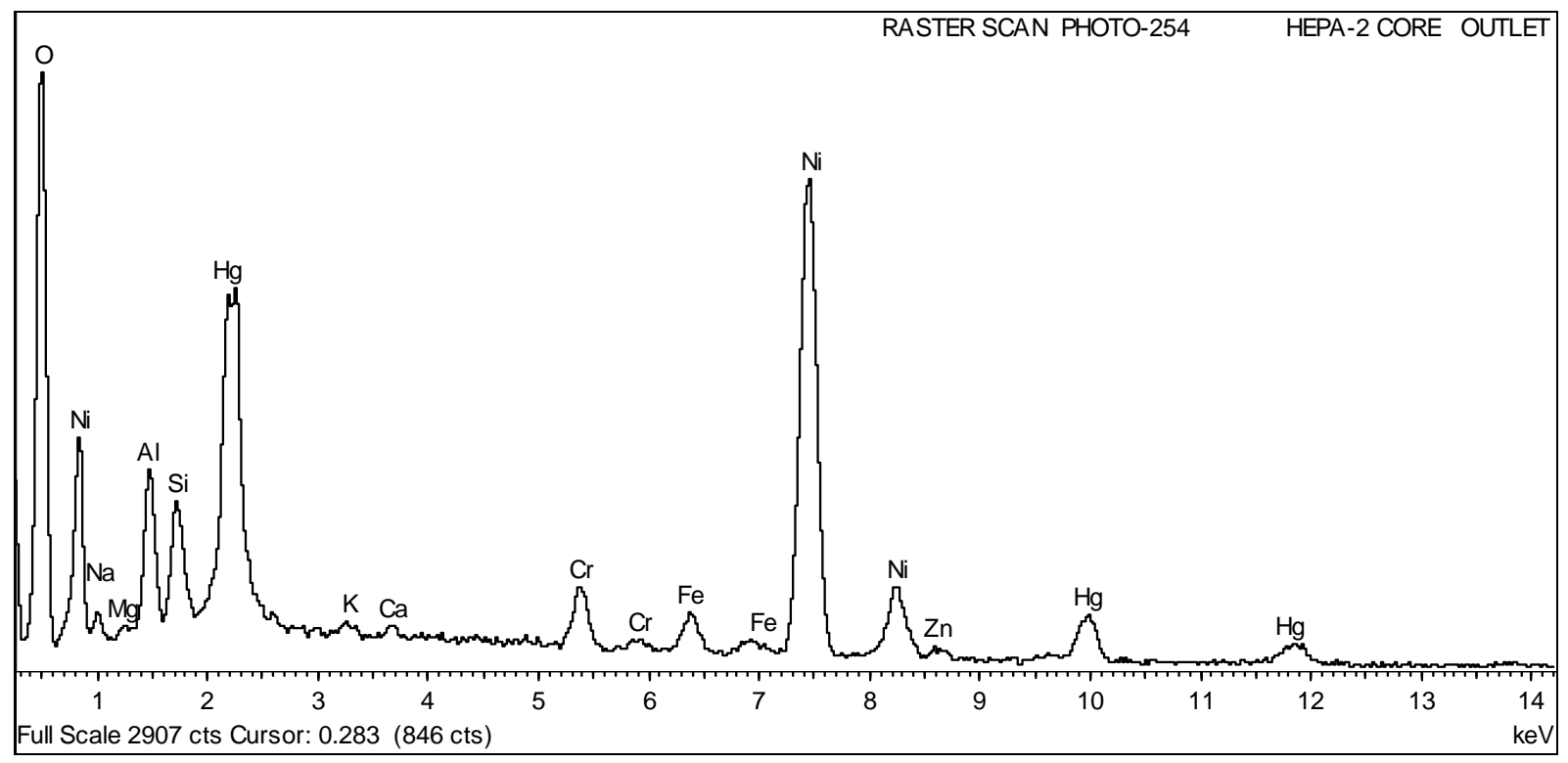

Figure 47. SEM EDX raster scan spectrum of the elements found in the HEPA-2 area outlined in Figure 46 


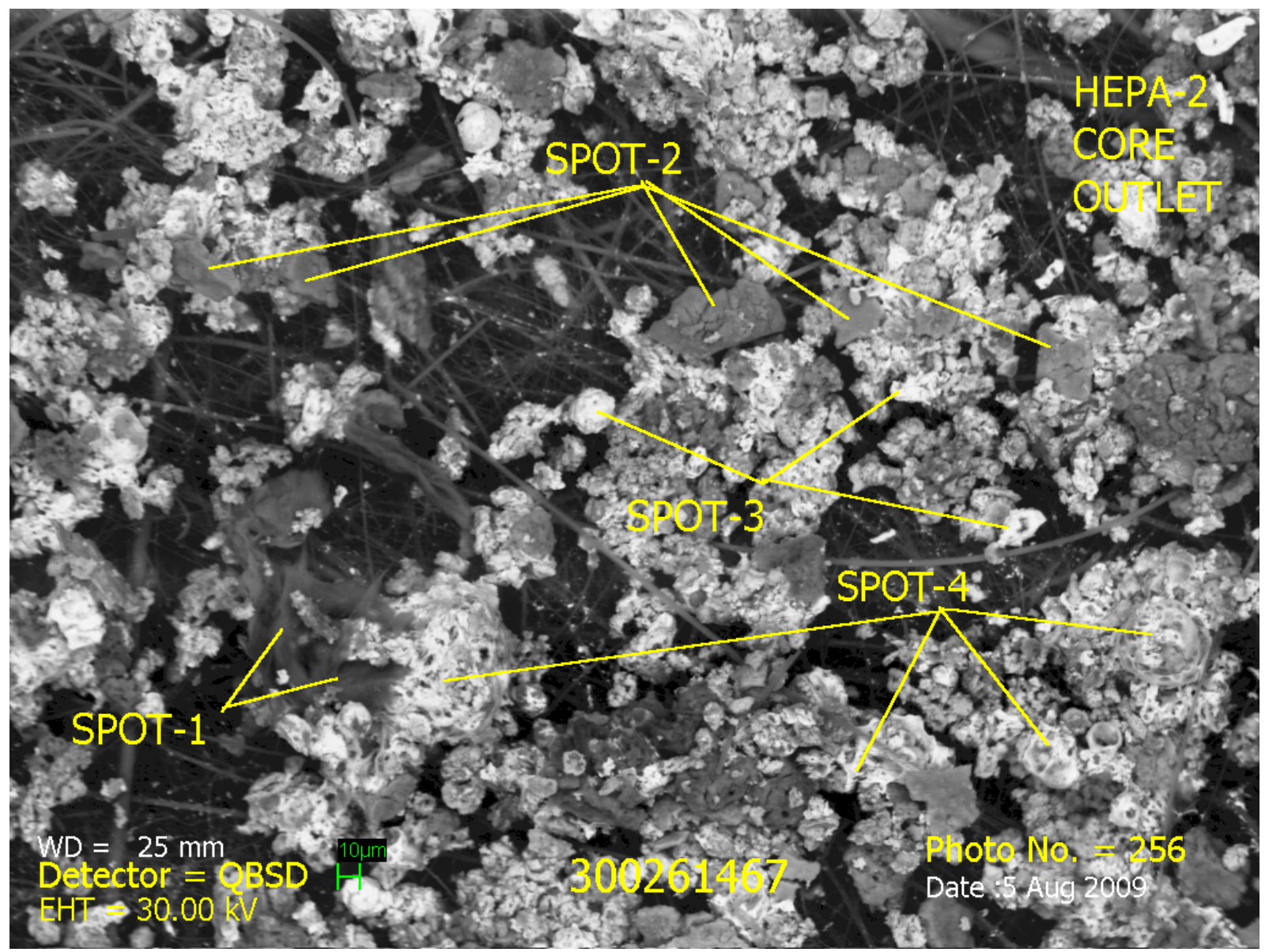

Figure 48. SEM image of DWPF GC Line Filter Assembly HEPA-2, Outlet side, filter media

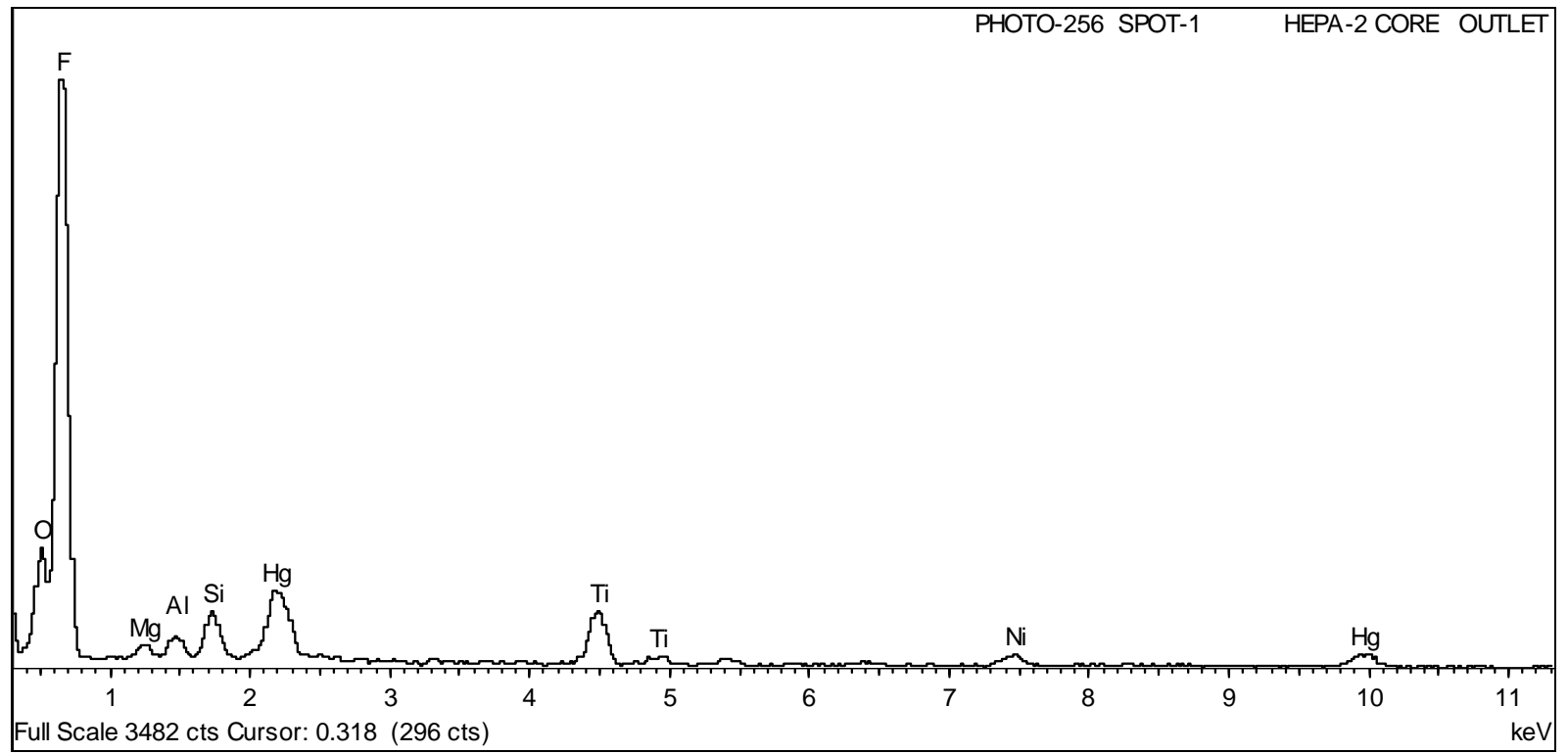

Figure 49. SEM EDX spectrum of HEPA-2, Spot 1 in Figure 48 


\subsection{Analytical Results}

A sample of $0.042 \mathrm{~g}$ of the solids collected from the outlet side of the HEME were dissolved in approximately $5 \mathrm{~mL}$ of $0.06 \mathrm{M} \mathrm{HNO}_{3}$ and submitted for cold vapor atomic absorption spectroscopy (CVAA) analysis for $\mathrm{Hg}$ and inductively coupled plasma atomic emission spectroscopy (ICP-AES) for elemental analysis. Since the sample did not dissolve in DI water, it was not submitted for ion chromatography (IC) analysis. The elemental composition of the solids is given in Table 2 and shows that the material is approximately $59 \mathrm{wt} \% \mathrm{Hg}$ on a total solids basis.

Table 2. Elemental composition of the white solids obtained from the DWPF GC Line Filter Assembly

\begin{tabular}{ccc}
\hline Element & Wt\% of Total Solids & \%RSD \\
\hline $\mathrm{Al}$ & 0.016 & 18 \\
$\mathrm{~B}$ & 0.038 & 0.6 \\
$\mathrm{Ca}$ & 0.026 & 1.4 \\
$\mathrm{Fe}$ & 0.011 & 3.5 \\
$\mathrm{Hg}$ & 59 & $\mathrm{NA}$ \\
$\mathrm{Mg}$ & 0.0077 & 0.2 \\
$\mathrm{Mn}$ & 0.0015 & 6.2 \\
\hline $\mathrm{Na}$ & 0.25 & 0.9
\end{tabular}

A sample of these solids was submitted for x-ray diffraction (XRD) and the resulting spectrum obtained is given in Figure 50. The material is a mix of two $\mathrm{Hg}$ species, $\mathrm{Hg}_{4}(\mathrm{OH})\left(\mathrm{NO}_{3}\right)_{3}$ and $\mathrm{Hg}_{10}(\mathrm{OH})_{4}\left(\mathrm{NO}_{3}\right)_{6}$. The sharp peaks indicate the materials were fairly crystalline. Both compounds are $\mathrm{Hg}$ (I) species.

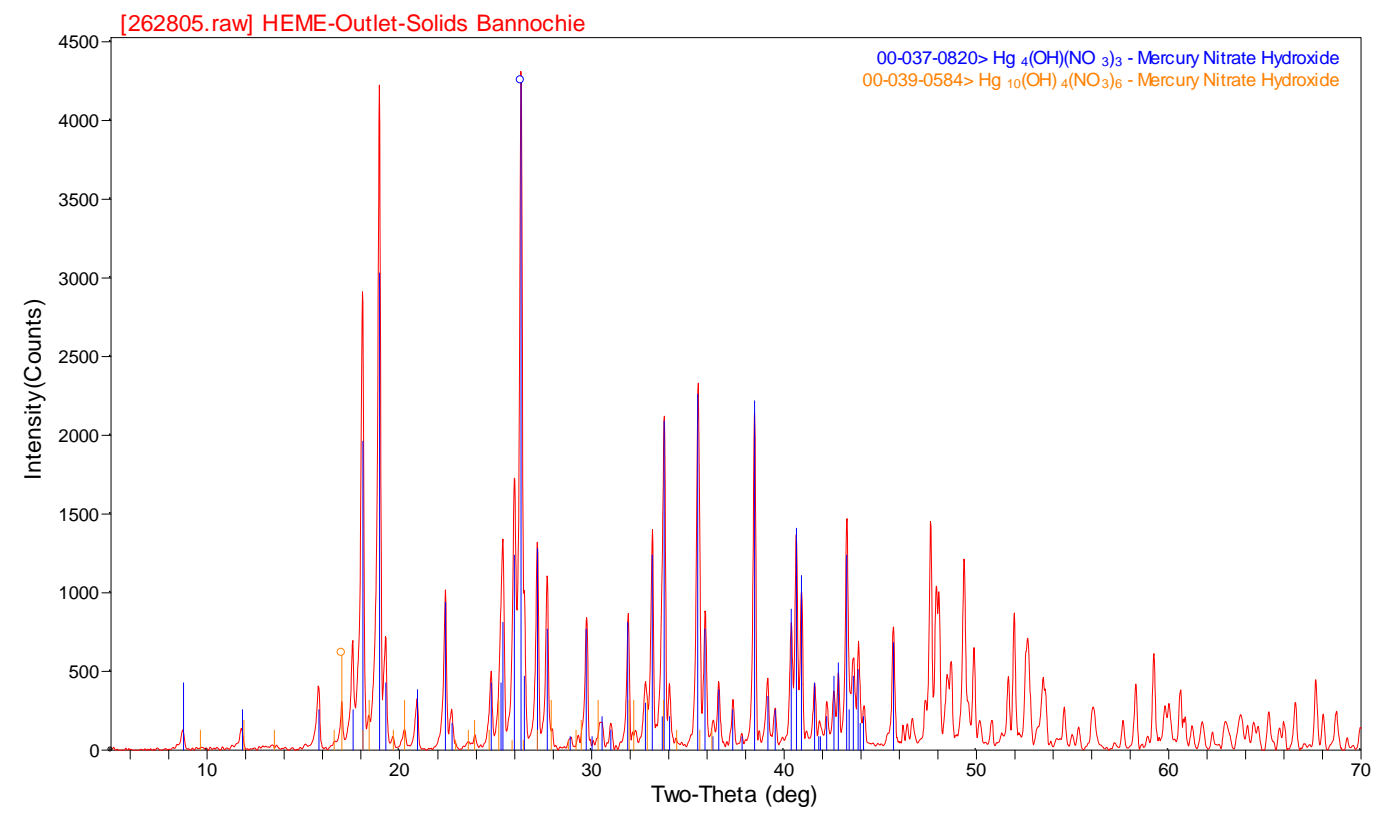

Figure 50. X-ray diffraction spectrum from white solids collected from the HEME outlet of the DWPF GC Line Filter Assembly 
SRNL-STI-2009-00602

Revision 0

This page intentionally left blank. 


\subsection{DISCUSSION}

\subsection{Filter Deposits}

From the observations obtained here, the vast majority of filter deposits are due to the $\mathrm{Hg}(\mathrm{I})$ compounds identified in Figure 50. The presence of $\mathrm{Hg}(\mathrm{I})$ species is due either to volatilization prior to complete reduction to $\mathrm{Hg}(0)$ in the Slurry Receipt Adjustment Tank (SRAT) or re-oxidation in the ammonia scrubber after contact with the Slurry Mix Evaporator Condensate Tank (SMECT) liquid. Since the system is designed to remove $\mathrm{Hg}$ and collect it into the Mercury Water Wash Tank (MWWT), this behavior would be considered outside the design criteria.

While the material is found in all three components of the GC Line Filter Assembly (HEME, HEPA-1, and HEPA-2), the first location of significant buildup is on the outlet side of the HEME. Initially, it was thought this may be connected to HEME flushes through the available water inlet that exists after the HEME filter material, but we have since learned that this flush capability is not currently used and was not used when this filter was in service. Why the solids accumulate here in larger quantities is not known, but it is apparent that the mist eliminator is not efficient at trapping these compounds.

The solids that build-up at the inlet side of HEPA-1, as compared with the outlet side, are probably carryover from the solids condensing after the HEME. The fact that solids are more evenly distributed throughout HEPA-2 might indicate that they are not condensing in large degree until this stage of the GC Line Filter Assembly. The even distribution of solids through this final filter stage would indicate that there is likely breakthrough with additional solids condensing after the HEPA-2. Alternatively, the backflow purges that have been attempted to improve flow through the GC Line may have altered the distribution of solids in the filters and or blown solids back down the line from the outlet to the inlet side of HEPA-2.

Since the GC Line Filter Assembly sample stream is a subset of the gas flow following the ammonia scrubber, it is likely that the SMECT liquid at $\mathrm{pH} \mathrm{3,} \mathrm{which} \mathrm{passes} \mathrm{through} \mathrm{the} \mathrm{ammonia} \mathrm{scrubber,} \mathrm{is}$ acidifying the gas stream, and the nitrate oxidizing the $\mathrm{Hg}(0)$ vapor to $\mathrm{Hg}(\mathrm{I})$. This material then begins to condense as it moves through the filters of the GC Line Filter Assembly. The remainder of the gas flow that is not directed to the GC Line would proceed to the Formic Acid Vent Condenser (FAVC) HEME, Process Vessel Vent (PVV) filter, and then on to the sand filters. Since a HEME appears to not effectively trap the two compounds we have identified, those condensing solids in the bulk of the gas stream are probably collecting at the PVV filter or the sand filter.

\subsection{Historical Hg Compounds in Offgas Lines}

It is not surprising to see $\mathrm{Hg}$ in these filters due to the high volatility of $\mathrm{Hg}$ compounds. During Integrated DWPF Melter System (IDMS) campaigns with Hg containing simulated sludge at TNX, elemental Hg was detected past the Sludge Receipt and Adjustment Tank (SRAT) condenser. ${ }^{2}$ Hg species were also observed in a SRAT GC instrument sample collected by DWPF in 2007. ${ }^{3}$ Due to the small sample size received in 2007, it was not possible to make a definitive determination of the species plugging the GC Line at that time. The best fit to the limited XRD data signal was another $\mathrm{Hg}(\mathrm{I})$ species, clearcreekite, $\mathrm{Hg}_{3} \mathrm{CO}_{3}(\mathrm{OH}) \cdot 2 \mathrm{H}_{2} \mathrm{O}$, but much of this sample appeared to be amorphous $\mathrm{Hg}$ species. 


\subsection{Evaluation of Total Hg Present}

After the characterization work on the sample was completed and the assembly materials returned to DWPF for disposal, a question arose as to the total quantity of these $\mathrm{Hg}$ compounds contained in the components of the GC Line Filter Assembly. This question was not evaluated for the work requested in the TAR. It may be possible to make an educated guess of the upper bound mass of material in the filters, but a more exact estimate is not possible with the information collected here. Since the material is soluble in $0.06 \mathrm{M}$ nitric acid, an acid flush of the filter media could remove the vast majority of the $\mathrm{Hg}$ from the components should this be necessary prior to disposal. 


\subsection{CONCLUSIONS}

The vast majority of the material in each of the three stages of the DWPF GC Line Filter Assembly appears to be contaminated with a $\mathrm{Hg}$ compound that is $\sim 59 \mathrm{wt} \% \mathrm{Hg}$ on a total solids basis. The $\mathrm{Hg}$ species was identified by XRD analysis to contain a mixture of $\mathrm{Hg}_{4}(\mathrm{OH})\left(\mathrm{NO}_{3}\right)_{3}$ and $\mathrm{Hg}_{10}(\mathrm{OH})_{4}\left(\mathrm{NO}_{3}\right)_{6}$. Only in the core sample of the second stage HEPA, did this material appear to be completely covering portions of the filter media, possibly explaining the pressure drops observed by DWPF. The fact that the material migrates through the HEME filter and both HEPA filters, and that it was seen collecting on the outlet side of the HEME filter, would seem to indicate that these filters are not efficient at removing this material.

Further SRAT off-gas system modeling should help determine the extent of Hg breakthrough past the MWWT. The SRAT off-gas system has not been modeled since startup of the facility. Improvements to the efficiency of $\mathrm{Hg}$ stripping prior to the ammonia scrubber would seem to be the only way to prevent/mitigate the formation of the compounds found in the GC Line Filter Assembly filters and therefore prevent pluggage of this filter assembly. 
SRNL-STI-2009-00602

Revision 0

This page intentionally left blank. 


\subsection{REFERENCES}

1. Wingard, B. R., GC Filter Assembly Sample and Analysis: Technical Assistance Request, HLEDWPF-TAR-2009-002, Savannah River Site, Aiken, SC 29808 (2009).

2. Hutson, N. D., Zamecnik, J. R., Smith, M. E., Miller, D. H., and Ritter, J. A., Integrated DWPF Melter System (IDMS) Campaign Report: Mercury Operations, WSRC-TR-91-0363, Savannah River Site, Aiken, SC 29808 (1991).

3. Zeigler, K. E. and Bibler, N. E., Analysis of DWPF SRAT Off-Gas GC Sample Line Debris, SRNLPSE-2007-00095, Savannah River Site, Aiken, SC 29808 (2007). 
SRNL-STI-2009-00602

Revision 0

This page intentionally left blank. 


\subsection{ACKNOWLEDGEMENTS}

The authors would like to acknowledge the support of the SRNL Shielded Cells technicians and supervision in order to move the components around SRNL, the assistance of Kevin Kalbaugh in obtaining samples from the filters, and $\mathrm{AD}$ for analytical assistance. 


\section{Distribution:}

S. L. Marra, 773-A

A. B. Barnes, 999-W

D. A. Crowley, 773-43A

S. D. Fink, 773-A

J. H. Scogin, IV, 773-A

B. J. Giddings, 786-5A

C. C. Herman, 999-W

F. M. Pennebaker, 773-42A

D. K. Peeler, 999-W

M. E. Stone, 999-W

N. E. Bibler, 773-A

J. M. Pareizs, 773-A

A. S. Choi, 773-42A

J. R. Zamecnik, 999-W

N. C. Iyer, 773-41A

T. M. Adams, 773-41A

K. E. Zeigler, 773-42A

K. J. Imrich, 773-A

J. E. Occhipinti, 704-S

J. W. Ray, 704-S

J. F. Iaukea, 704-30S

R. T. McNew, 704-27S

M. C. Clark, 704-27S

J. M. Bricker, 704-27S

H. M. Pittman, 704-27S

B. R. Wingard, 704-27S

P. M. Woodward, 704-27S

T. L. Fellinger, 704-26S

E. W. Holtzscheiter, 704-15S

S. G. Phillips, 704-15S

H. H. Elder, 704-24S 